\title{
Excavations at Upper Suisgill, Sutherland
}

\author{
G J Barclay* \\ with contributions by Martha V Andrews, Anne M Blackham, \\ D Gilbertson, Jenny A Lee, and Marijke van der Veen \\ and illustrations by J S Rideout and Angela Townshend
}

\section{SUMMARY}

A narrow section across an area between two souterrains was excavated in advance of road realignment; part of one of the souterrains was also exposed. The excavation revealed deposits up to $c$ $1.8 \mathrm{~m}$ deep in places, largely made up of material washed downhill on to the site.

Early-mid first millennium bc: Period I-ard tillage; $I I$ - construction and reconstruction of a round timber house, and the erection of a stone-faced earth bank; III - tillage; IV - the construction, and destruction by fire, of a post-built structure; beginning of water scouring of the site and start of hillwash deposition.

Settlement was re-established later in the millennium on the surface of the hillwash deposits (Period VI). This was subsequently covered by more hillwash. Recent settlement was represented by uncharacterized activity at the south edge of the excavated area and by two post-medieval buildings (associated with a settlement to the $S E$ ) the later of which was probably demolished during 19th-century road building.

Quantities of pottery of 10 fabrics and three main styles (1, flat rims; 2 , splayed rims; 3 , everted rims) were found. Carbonized plant material was recovered, including many grains of six-row (mainly naked) barley, a little wheat, and oats, possibly domesticated. The pollen analysis of a peat column taken from a bog $2 \mathrm{~km}$ from the site showed a notable forest decline at c $4500 \mathrm{bp}$, followed by a pinebirch regeneration, followed, shortly before 1700 bp, by a further decline.

\section{1: DESCRIPTION}

INTRODUCTION

The failure of the bridge carrying the A897 over the Suisgill Burn in the Strath of Kildonan, Sutherland (illus 1) in 1978 led the Highland Regional Council to propose the realignment of the road and the construction of a new bridge downstream (illus 2). During preliminary investigations in August of the same year on the proposed road line, to determine the nature of the subsoil, a stone slab was struck, $0.6 \mathrm{~m}$ below the modern topsoil surface (illus 3 ). It was realized that this was probably the roof of a souterrain. The Scottish Development Department (Ancient Monuments Division) subsequently negotiated a road line which avoided the structure. Increased cost prevented the route of the road being displaced to the south; it was therefore moved to the north, between the newly discovered souterrain (Suisgill III) and the remains of another, previously known, immediately to the north of HBM (SDD), 20 Brandon Street, Edinburgh 


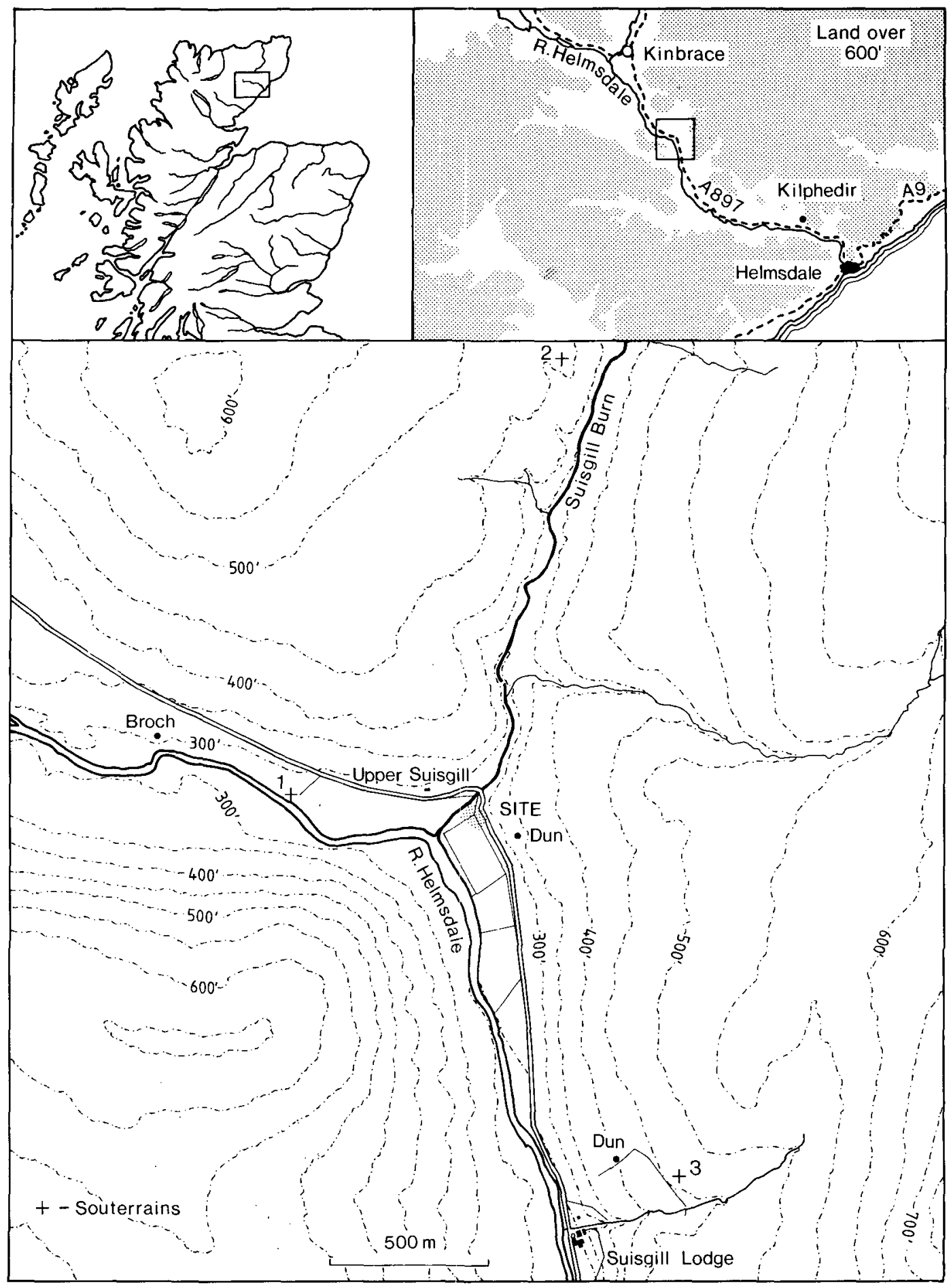

ILlus 1 Location maps: 1, Suisgill I; 2, Allt bad Ru'fin; 3, Ach na Fhionnphuaraidh 
the old road (Suisgill II). The occurrence of contemporary settlement in the area between the two was considered sufficiently likely to justify excavation in advance of the roadworks. In the early summer of 1980 , after an inconclusive resistivity survey, a six-week excavation was carried out by the Central Excavation Unit of the Ancient Monuments Division; a further six weeks' work took place in the autumn of that year, followed by a two-week salvage excavation in the spring of 1981, as the road was being built.

\section{BACKGROUND AND PERIOD SUMMARY}

The site lay on the inner edge of the terrace of the River Helmsdale, on the south bank of the Suisgill Burn, some $150 \mathrm{~m}$ from their confluence (NGR NC 897 251, illus 1 \& 2). Prior to excavation certain topographic features were noted. On the proposed route of the realigned road (illus 3 ) lay an earlier track, on a raised bank diverging at its south-eastern end from the route of the present A897. Its level dropped towards the north-west where, at the edge of the river terrace, the track descended into a narrow defile leading to the bank of the Suisgill Burn. In the corner of the field immediately to the south-west of the site was a low bank, running from the south-east to the west, towards the souterrain (Suisgill III). Immediately to the north of the field wall three low banks were visible, one possibly the extension of that noted in the field.

Before work began it was assumed that any surviving settlement evidence would lie close to the

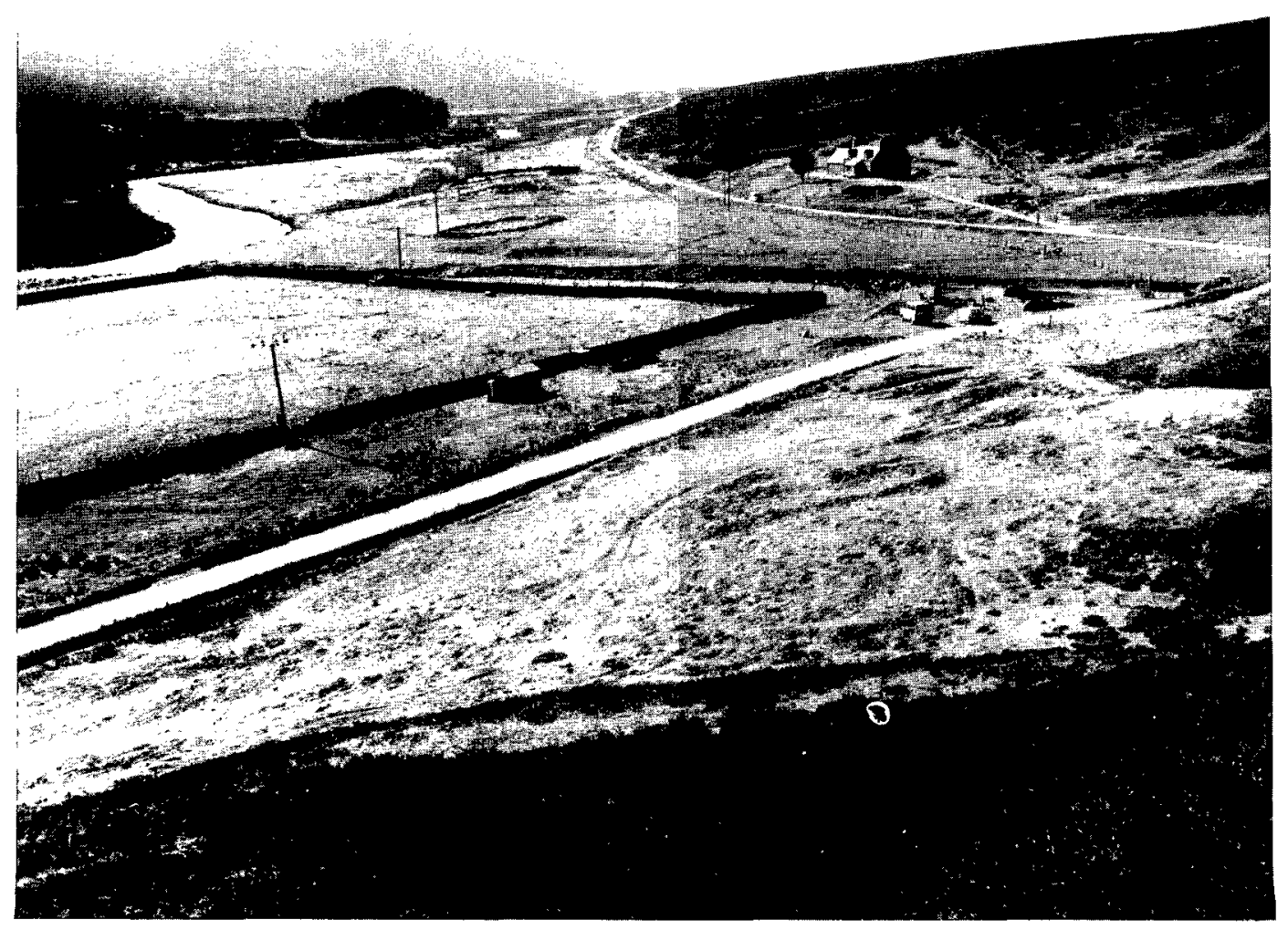

ILLus 2 The site from the dun to the south-south-east 
surface. On the hillside to the south-east of the threatened area the remains of a number of rectangular buildings, probably of post-medieval date, were noted, and it seemed likely that any prehistoric settlement which might exist would have been disturbed. However, the site turned out to be rather more complex than had at first been thought. A series of hillwash episodes had covered the earliest settlement evidence. Within the hillwash deposits, episodes of later occupation were discovered, culminating in the erection and destruction of post-medieval buildings and the construction of modern roads on top of the hillwash.

The following sequence of events was discovered:

Period I Tillage represented by ard-marks surviving under an earthen bank at the south-eastern end of the site in area $\mathrm{A}$.

Period II A timber-framed building was erected in area B and, to its south-east, an earthen bank, stone-faced on one side, was constructed. The building was then reconstructed on almost the same plan. Early first millennium $b c$.

Period III Tillage was resumed over the site of the house.

Period IV A post-built structure was erected over the site of the Period II house; it extended on to the top of the bank. The structure was burnt.

Period V Ard-cultivation was resumed over the house site and commenced over the stone-faced bank, by then buried by soil creep. Later a wall was built on the line of this earlier bank. The wall was added to once. There was further tillage.

The first severe water-scouring and hillwash deposition took place. Most occupation deposits were washed away in the north-western part of area B and in most of area C. A layer of gravel, washed from the hill to the east covered almost all of areas B and $C$ to the north-west of the wall on the line of the bank (Period V). Early/mid first millennium bc.

Period VI Settlement was re-established on top of the hillwash. At the south-eastern end it took the form of a series of stake- and post-built fences; to the north-west, in the water channel (illus 17) a group of postholes was found. Later, water once again flowed down the channel, the north and south edges of which were defined by low stone walls. The period ended with a further gravel inundation which affected all of areas $\mathrm{A}$ and $\mathrm{B}$ and most of $\mathrm{C}$. The souterrain was probably built in this period. Later first millennium $b c$.

Period VII Slight traces of a series of occupations found in the upper hillwash gravel, possibly the disturbed remnants of more substantial deposits.

Period VIII Recent occupation; road building.

\section{THE EXCAVATION}

In the first season areas A, C, D and F (illus 3) were excavated, wholly or in part. During the excavation it became clear that large areas were covered with hillwash material under which ardmarking was preserved. Small areas of the primary settlement were revealed and as a result the second season of excavation was undertaken. The investigation of areas $A$ and $C$ was continued and work began on the eastern part of area $B$. The stone-faced earthen bank under the $A / B$ baulk was found, and a narrow trench dug between the eastern part of $B$ and the east edge of $C$ revealed (under $1.9 \mathrm{~m}$ of gravel and topsoil) traces of timber structures. At the end of the second season it appeared that the features found under the gravel were too deep to be affected by the road-building and work therefore ceased. However, early in 1981 it became clear that the road would cut deeper than hitherto planned. Therefore a short salvage season was mounted to coincide with the removal of the gravel overburden (and the traces of Period VI settlement) in area B by the road builders. Only a slight 


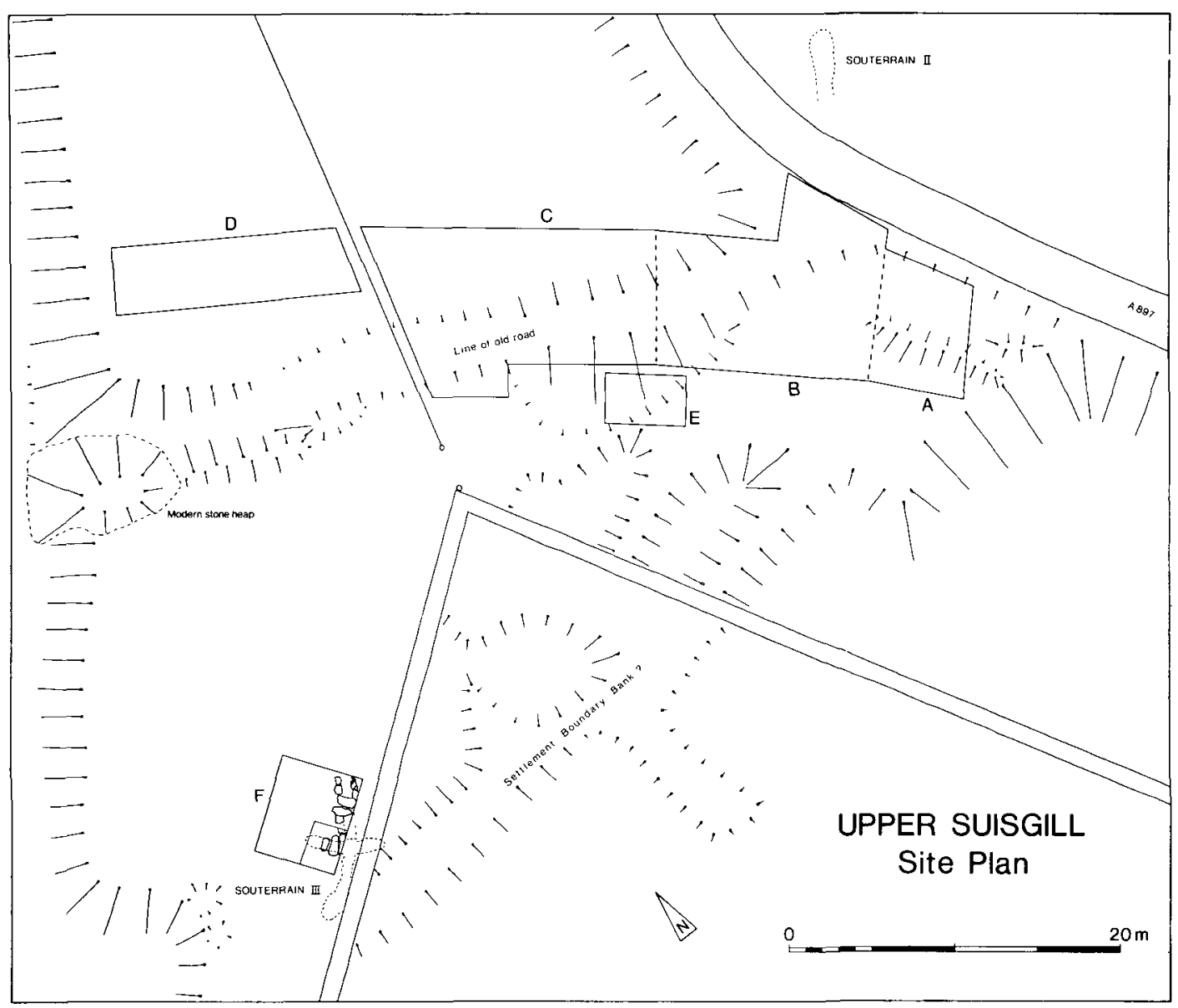

ILlus 3 Site plan

record of the material within the gravel in this area could be made and only a short time was available for the investigation of the evidence underneath the gravel, which consisted of the remains of three buildings and a complex series of agricultural horizons.

As a result of the unexpected depth of the deposits and the other complicating factors, combined with the limitations imposed by the area available for excavation, there was an unwelcome inconsistency in the approach to different parts of the site. Further, only a narrow strip of what must have been a relatively large site was excavated. These limitations should be borne in mind by the reader. Because of the variety of events occurring in different parts of the site, and the subsequent water damage, the evidence is difficult to describe in any sequence. The examination of structures which preceded the first gravel flow has been complicated by the cultivation and resultant disturbance of the soil in Periods III, and V, following the building phases (II and IV).

It has been convenient to split the description into the following parts:

A Period I and undated agricultural activity.

B Period II to Period V, settlement activity and later agriculture prior to ' $\mathrm{C}$ '. 

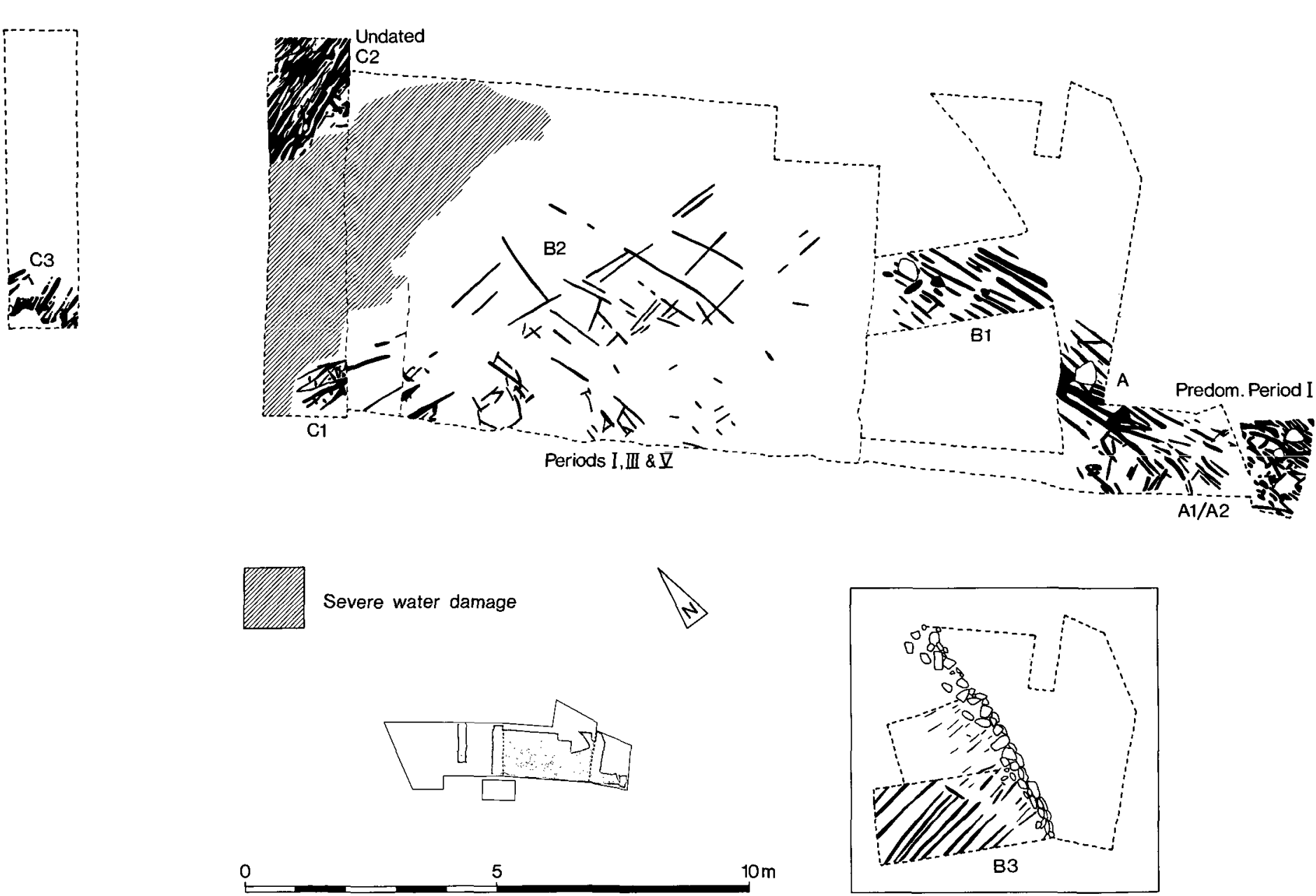

ILLuS 4 Plan showing area of water damage to subsoil and archaeological levels and the position of cultivation remains: Period I- A1, A2, B1; Period IIIB2; Period V - B3; Undated - C1, C2, C3 
i Houses $1 \mathrm{~A}$ and B (Period II)

ii The Bank (Period II)

iii House 2 (Period IV)

iv Wall 1 (Period V)

C Period V, first gravel inundation.

D Period VI settlement.

E Period VI/VIII, second gravel inundation.

F Period VI?, the souterrains.

G Recent occupation.

The description is followed by the artefact and other specialist reports, and the excavator's interpretation and discussion.

The creep of topsoil downhill (from NE to SW) in area A increased the depth of the humic layer to over $1 \mathrm{~m}$ against the boundary bank. As a result, tillage could be extended over the top of the bank in Period V.

\section{A: Agriculture 1 - Period I and Undated}

There are four distinct groups of ard-marking: (i) undatable, (ii) Period I, (iii) Period III, (iv) Period V. The last two are discussed in section B as they affect and are affected by the Period II and IV settlement activity. The ard-marks of Period I and of indeterminate period were preserved in scattered patches along the entire length of the main site (areas $A$ to $E$; illus $4 \& 5$ ). At the south-east, in area B, a north-south set (B1) was sealed, with traces of a (?later) east-west set under the Period II

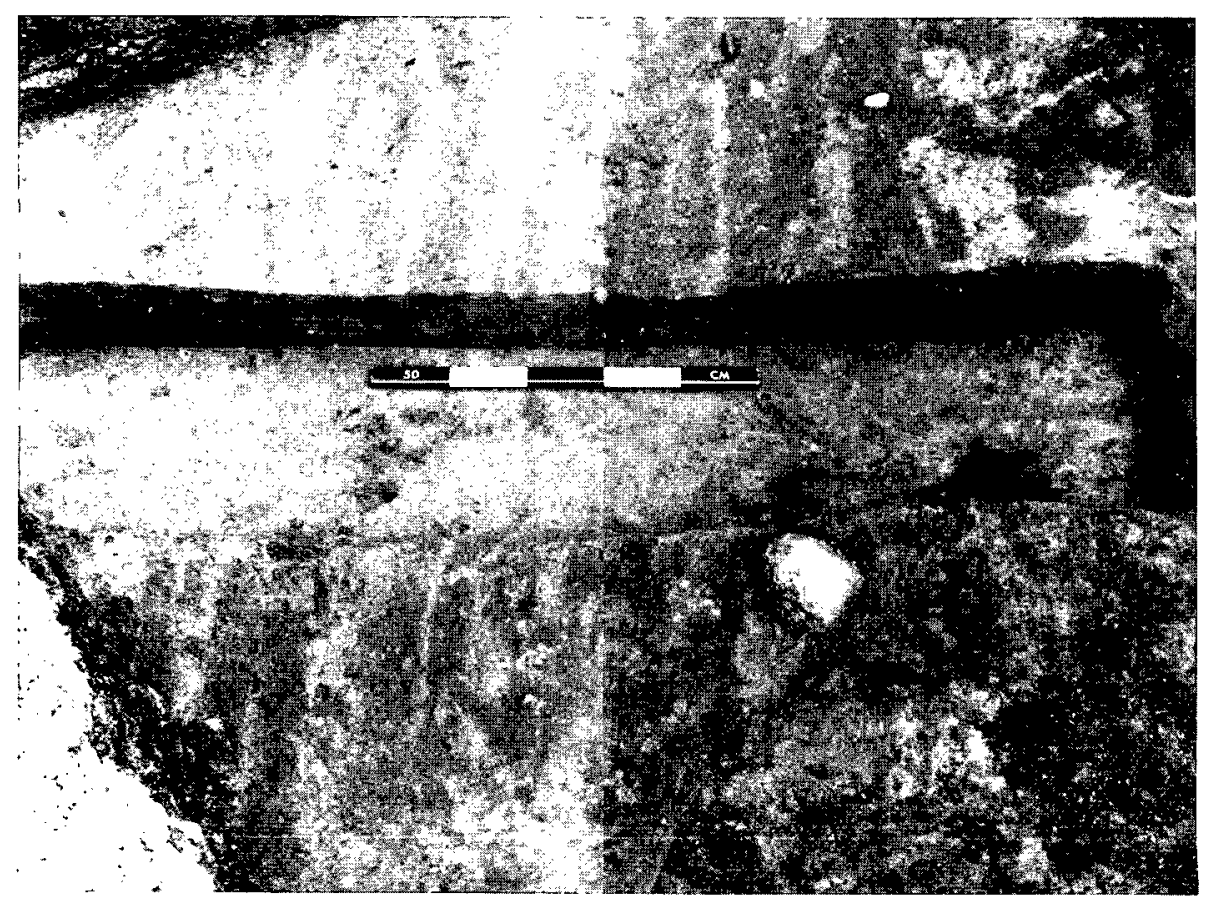

ILLus 5 Ard-marks (set A1/A2) in area A, from SW 
bank. Immediately to the south-east in area A the sets continued (N-S: A1); slight trace E-W (A2; illus 5). There were apparently no ard-marks of this period surviving between set $B 1$ and area $C$. In area $C$ there were three separate groups of ard-marks, each isolated and damaged to a greater or lesser extent by the water flows of Period V. In the south corner was a set (C1) which included northsouth and east-west marks, and possible spade-marks (described below). Part of this set may be associated with the markšin area $\mathrm{B}$ (infra). In the east corner a very dense set (C2), almost exclusively east-west was found. The close spacing of the marks may indicate more than one episode of east-west ploughing. Slightly to the north-west a further set was found, the marks running E-W (C3). In area D an extensive area of marks was noted in the first season, on the subsoil surface immediately under the topsoil (D1, illus 6); in the first season they were interpreted as recent. Little can be said about the possible spade-marks in area $\mathrm{C}$ (illus 7); they measured between $12 \mathrm{~cm}$ and $18 \mathrm{~cm}$ in length and were up to $4 \mathrm{~cm}$ deep. Further possible spade-marks were noted in area $\mathrm{A}$.

\section{B: Settlement activity and later agriculture prior to gravel wash of Period $\mathrm{V}$}

\section{Houses $1 A$ and $B$ (Period II)}

Plans and photographs of the features which make up this structure, wholly and partly excavated in the third, salvage, season are presented on illus 8-10. Most of the occupation material associated with the features had been severely disturbed by subsequent ploughing. The postholes shown on the plans were cut into the sand subsoil and formed no completely coherent shape. In several cases one posthole clearly cut another. Two ill-defined linear hollows filled with soil and stones were found near the edge of the feature spread. Charcoal samples from two postholes were

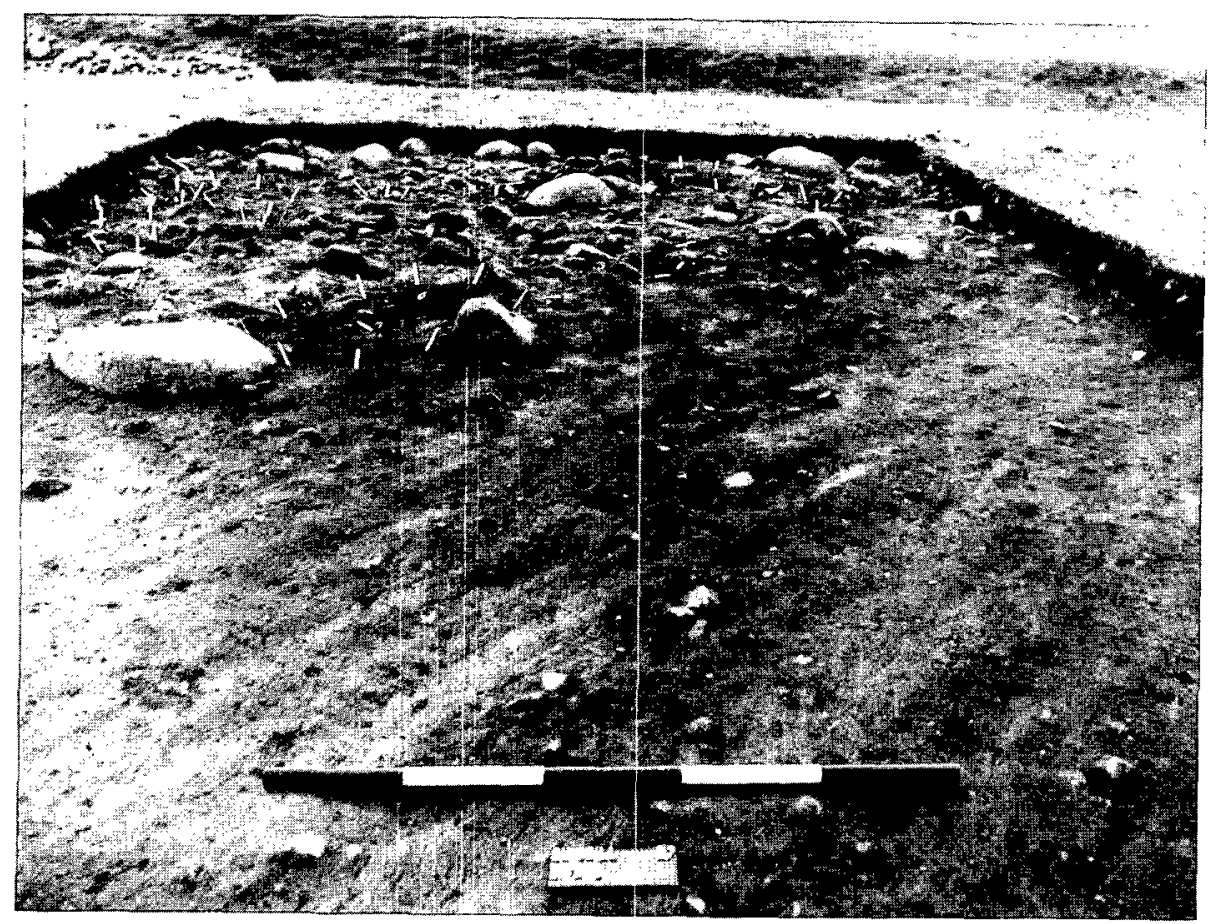

ILlus 6 Ard-marks (set D1) in area D, from SE; natural fluvioglacial deposit of rocks beyond 


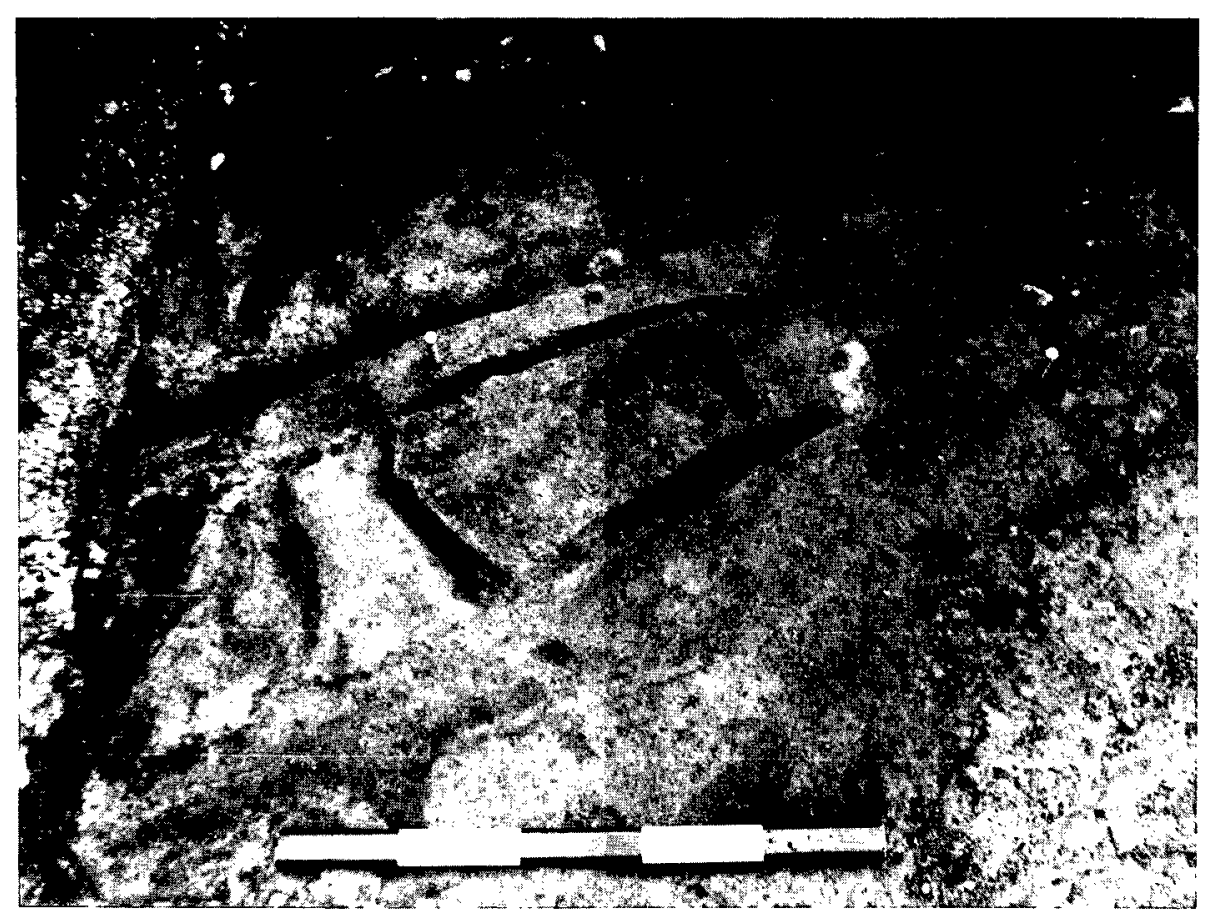

ILLUS 7 Ard-marks and spade-marks in area C

submitted for radiocarbon dating (structure 1a: $825 \pm 105 \mathrm{bc}$ (GU-1492); structure 1b: $885 \pm 90 \mathrm{bc}$ (GU1490)). To the south-west of the centre of the posthole group a damaged ' $U$ '-shaped stone setting was found (illus $8 \& 9$ ). The stones lined the lip of a small depression, probably a hearth. Within the depression and spilling over the stones was a deposit of burnt turf and charcoal; subsequent cultivation had spread and scattered this material. In the area of this supposed hearth and along the south-west edge of the excavated area was a concentration of stakeholes, some apparently set in lines. A further mass of stakeholes was also found around the north-west to north-east portion of the edge of the posthole concentration. Only a scattering of stakeholes was found elsewhere, though the absence of such features in the central area, to the north of the hearth may reflect the lower level of the subsoil there; ie the stakeholes may have been present in the subsequently mixed soils above, and not penetrated the subsoil. The great majority of the stakeholes were undatable. They may belong to either the House 1 complex or to House 2; they therefore appear on the plans of both (illus $8 \& 12$ ).

\section{The Bank (Period II)}

At the south-eastern end of area B was a low earthen bank, faced with stone on the southeastern side and sloping down gradually on the NW (illus 8). It covered one posthole, which could not, however, be related to the House 1/House 2 sequence (illus 11). The bank also sealed an old topsoil, which in turn overlay an ard-marked subsoil (Period I). The top of the bank displayed clear ard-marks (Period V; illus 4: B3) but this disturbance had not entirely destroyed other features on the bank top. These included shallow slots and two roughly parallel lines of stakes running along the line of the bank, joined, at the break between the grooves, by a broad mass of stakes. There were also the burnt remnants of stakes and other material (illus 12). 


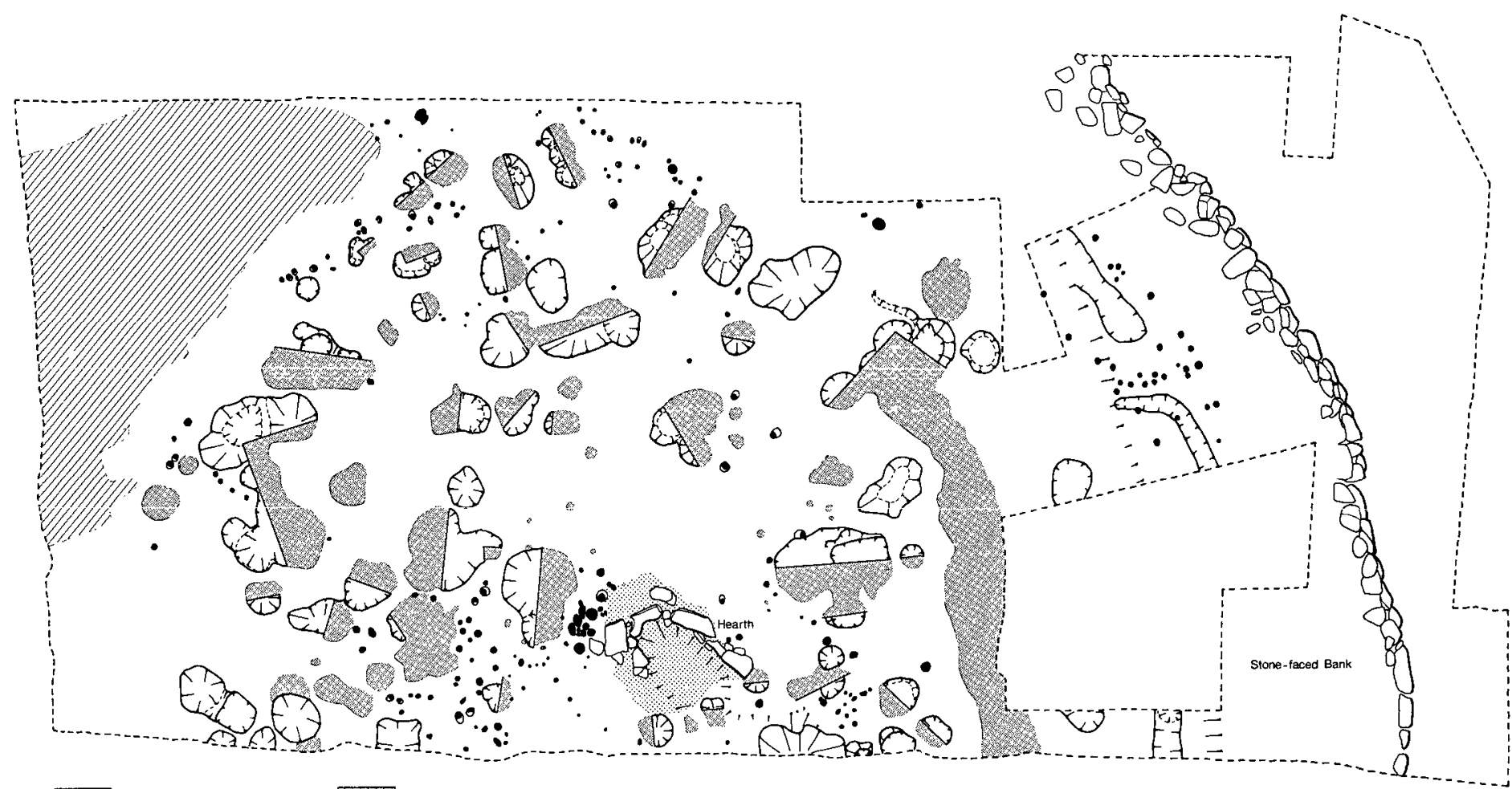

Burnt natural
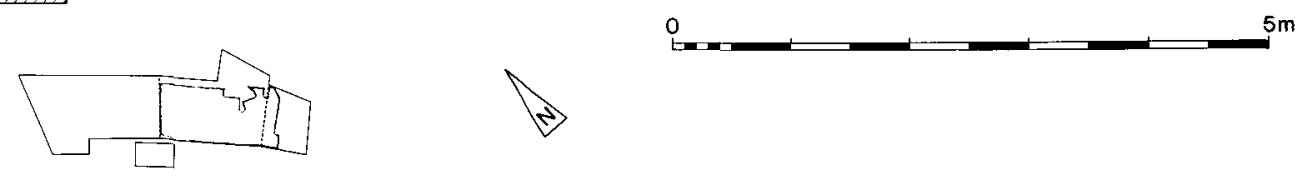

ILLus 8 Period II features at end of salvage season: houses 1A and 1B. The stakeholes and certain other features shown may be of this Period, or of house 2: Period IV (see illus 13) 


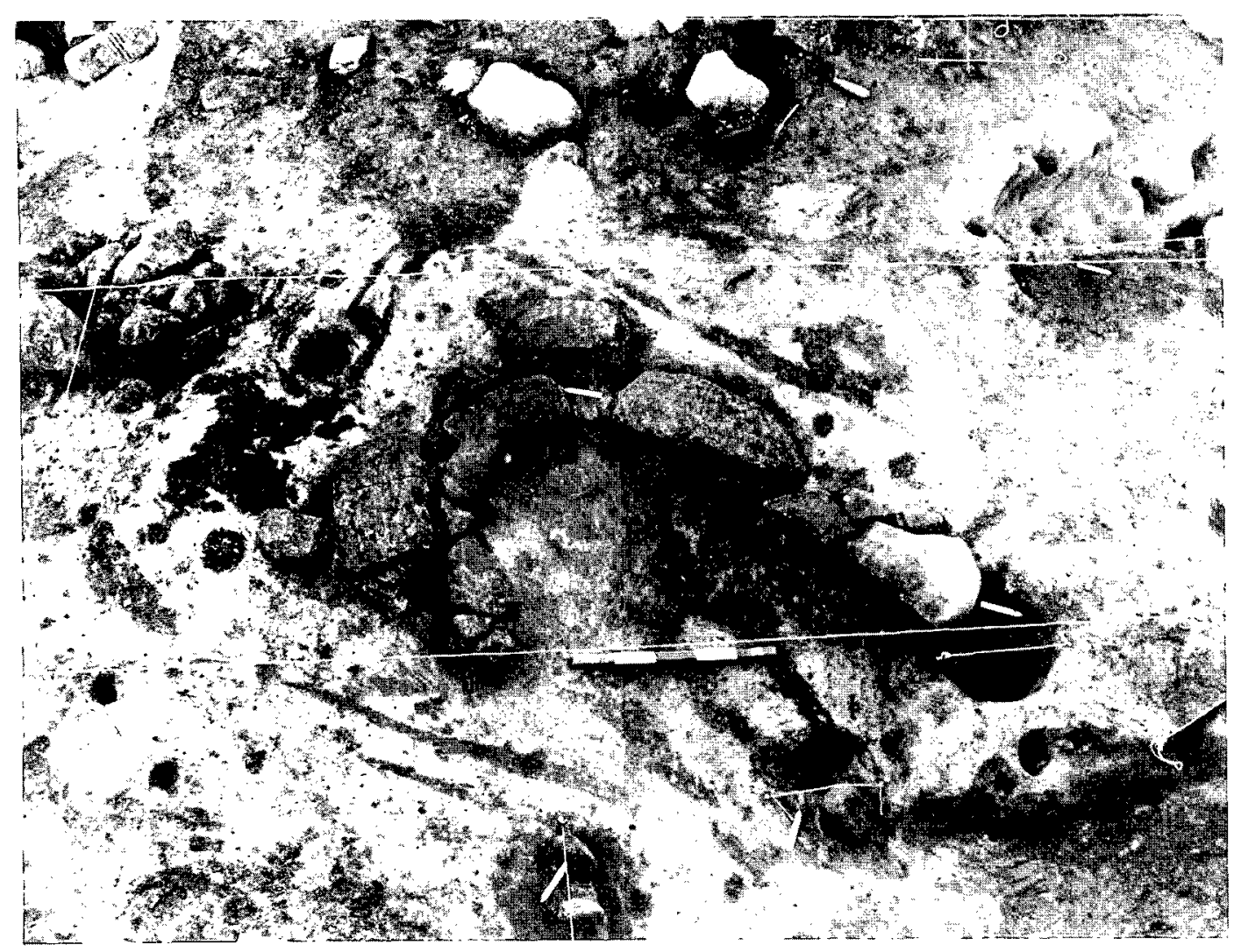

Iṭus 9 The hearth. Ard-marks are visible surrounding it

\section{House 2 (Period IV)}

Surviving only as four stone-packed postholes (marked A to D on illus 12) cut into the topsoil surface associated with the ard disturbance of House 1, was a second structure. The posts, which had been burnt in situ, were linked by a broad band of burnt material. The surfaces associated with this phase had subsequently been damaged by ard ploughing (Period V). Charcoal from one of the posts was submitted for radiocarbon dating: the resultant assay was $885 \pm 90$ bc (GU-1490).

It is suggested that the stakeholes on the bank top, and the burning found there, can be related to these burnt posts and the arc of disturbed burnt material linking them. The whole would be a timber house, burnt down and then ploughed over, the non stone-packed features off the bank being truncated; some of those in illus 8 may belong to this structure. Charcoal from the burnt debris on the bank yielded a radiocarbon date of $990 \pm 60$ bc (GU-1493).

\section{The Wall (Period V)}

On the surface of the ploughsoil which formed over the primary bank, a low stone wall was constructed (illus 11(d), 13 \& 16). It measured approximately $1.6 \mathrm{~m}$ broad and survived to a maximum height of $0.65 \mathrm{~m}$. Its front face was set back between $0.25 \mathrm{~m}$ and $0.40 \mathrm{~m}$ from the stone facing of the primary bank, which had been covered by hill creep by this stage. It did not continue, or 


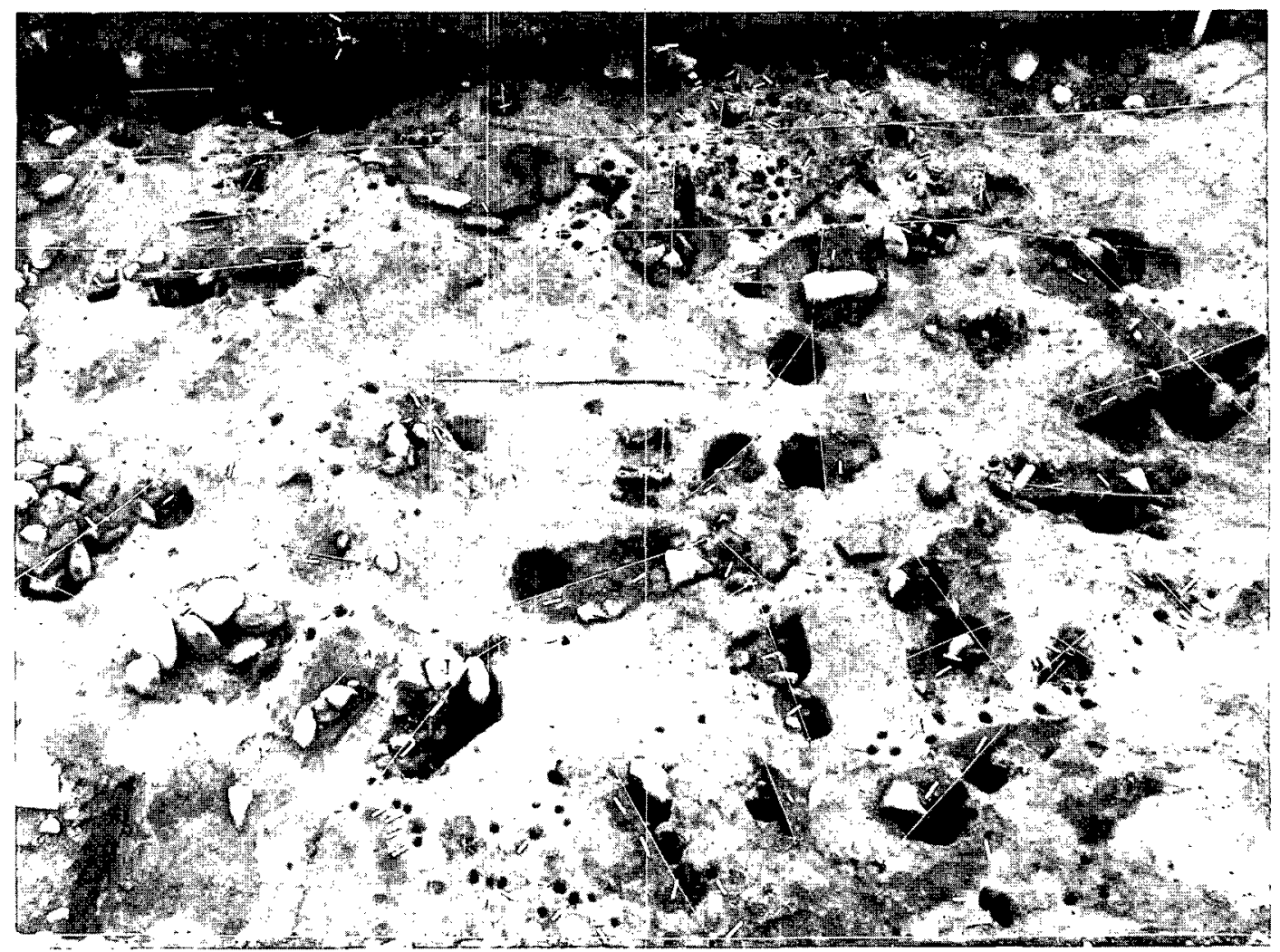

ILlus 10 House $1 \mathrm{~A}$ and $1 \mathrm{~B}$ at the end of the excavation from the NE
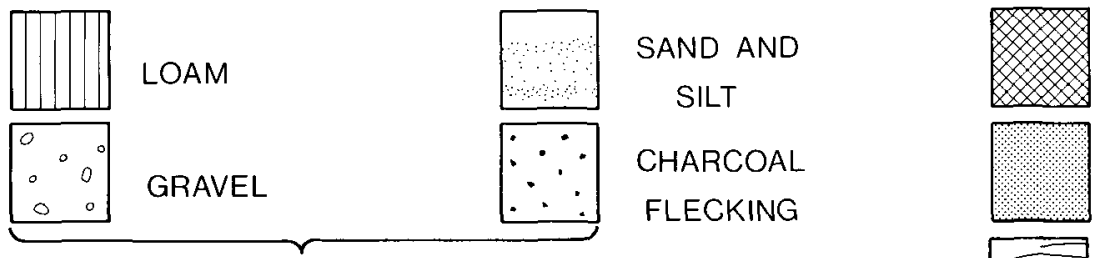

CHARCOAL

STAINING

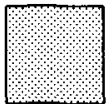

BURIED

TOPSOIL

May be combined

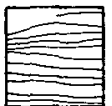

SAND AND

PEAT LENSES

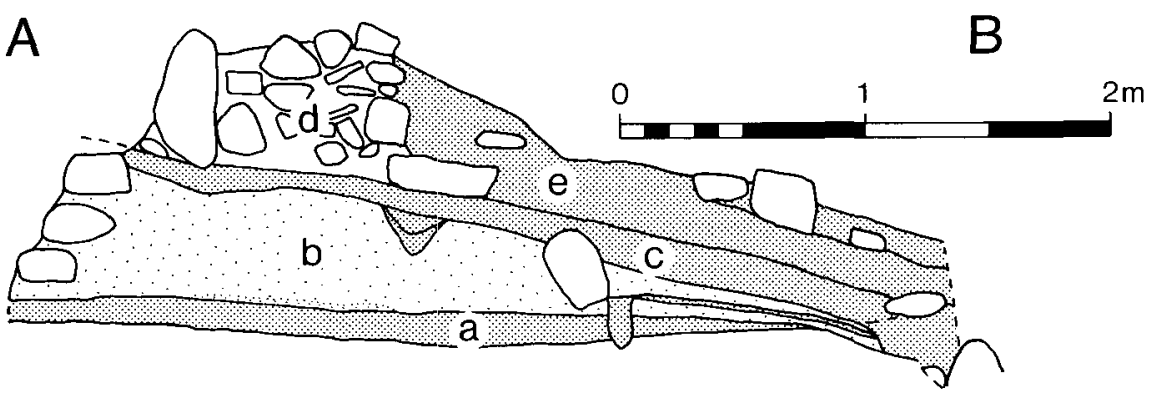

ILLus 11 Section through: a the first agricultural soil (Period I), b the stone-faced bank (Period II), c the soil over the bank (agricultural use in Period V), d the wall (later Period V), e soil build-up against 'd' prior to first gravel flow. The key is used in all the published sections. The position of the section is shown on illus 13. 


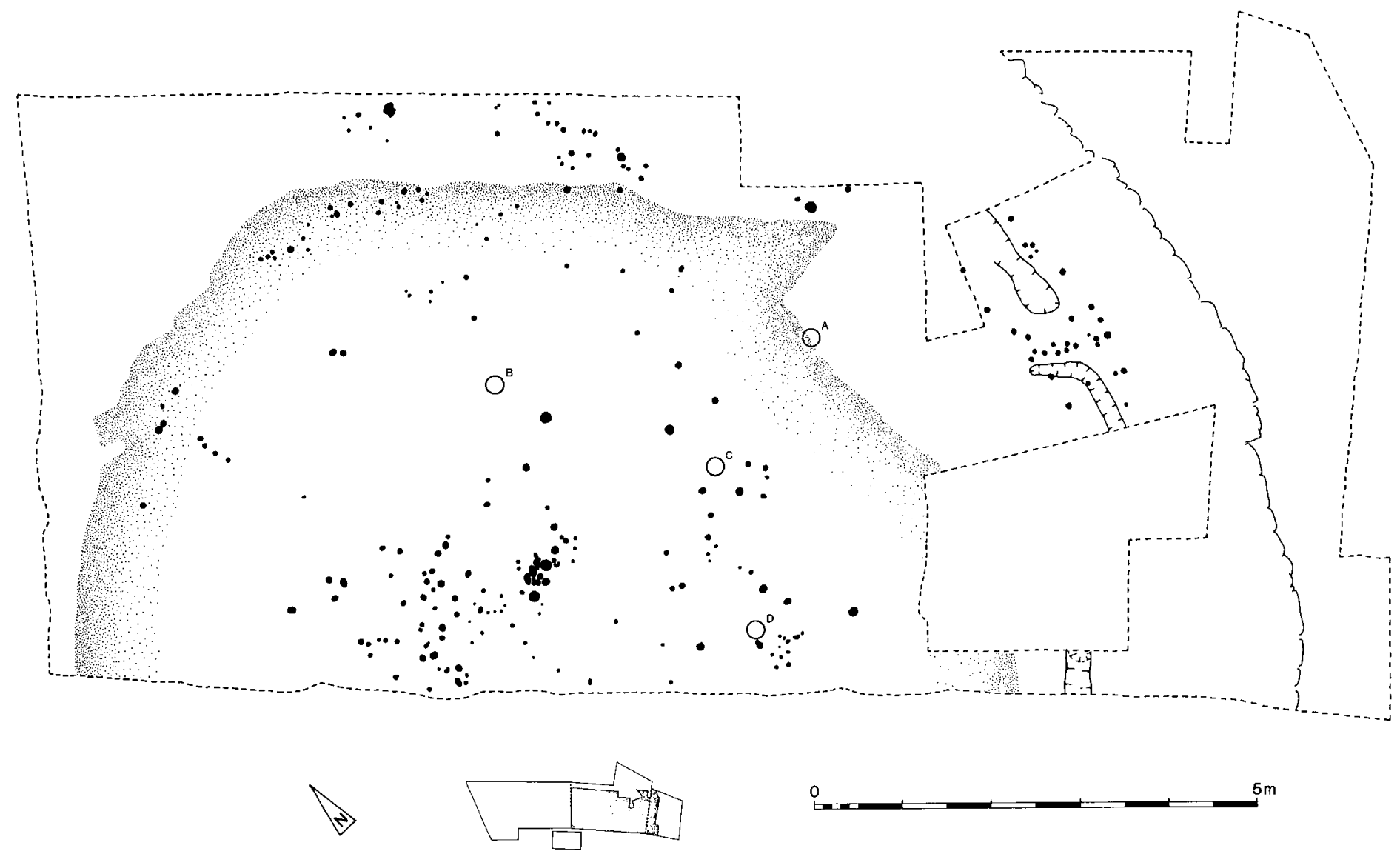

ILlus 12 Period IV structure (House 2), represented by four stone-packed postholes (A-D) containing the remnants of burnt posts; the remaining postholes seem to have been lost to Period V agricultural disturbance. The edge of the spread of burnt material, probably showing the approximate edge of the house, is shown by the stipple. The stakeholes were noted in the subsoil and may belong to the structure or Houses $1 \mathrm{~A}$ and $1 \mathrm{~B}$. Some of the postholes shown in illus 8 may also belong to the structure. 
at least it did not survive, as far to the north as the primary bank had done (see illus 13). Its west, rear, face was ill defined; further stone had been added later, in an irregular pile, to the north-west side near the south-west baulk. The wall survived to a height sufficient to prevent ard ploughing over it (illus 16).

In part $\mathrm{A}$, above, the contrast between the ard-marking under the primary bank and to the south-east was noted; both sets were mainly north-south with a slight presence of east-west marks but to the south-east, outside the area enclosed, a greater variety of directions was noted. To the south-east of the primary (stone-faced) bank and the later wall no traces of substantial structures were found. Soil-creep increased the depth of the topsoil from a few centimetres when the first ard-marks were made in the subsoil, to $\mathrm{cl} \mathrm{m}$ against the south-eastern side of the primary earth bank, which it eventually buried, facilitating ard cultivation over it in Period IV. A soil build-up was also noted against the later wall (Period V); part of the top of the Period V wall remained visible for some time. Within this build-up of soil one sand lens was found, immediately to the south-east of the bank. Faint ard-marking was noted in this lens, indicating the continued agricultural use of the soils. In the upper part of this deep accumulation of topsoil, a line of small stones was found, running NW-SE across area A (illus 14). At its north-western end it abutted the stone wall built over the primary bank. There was no difference in the soils to its north and south; it lay on topsoil and was covered by topsoil creep. The feature had been formed deliberately but was too insubstantial to have acted as a physical boundary.

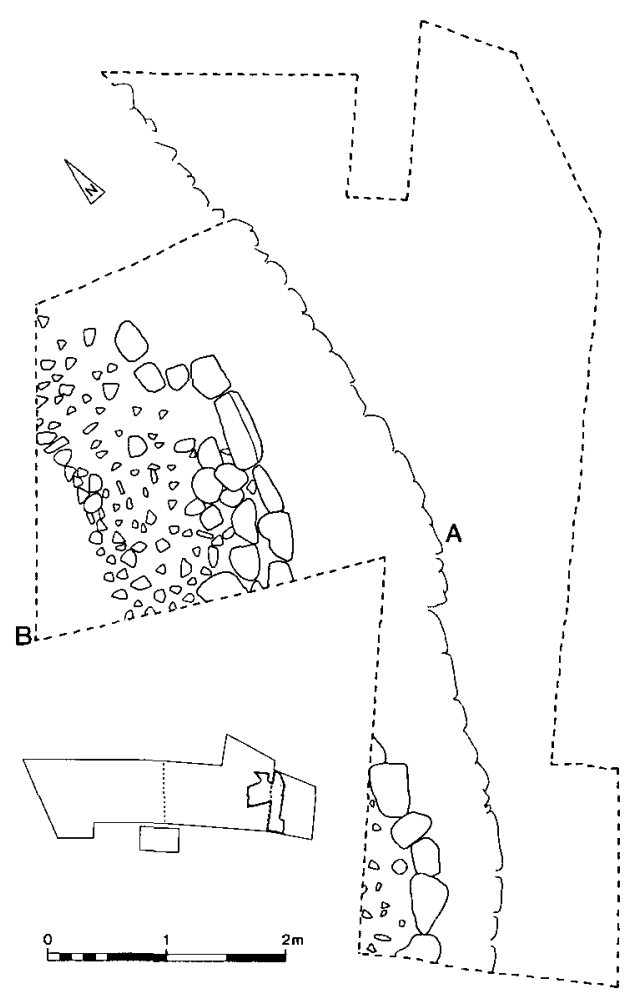

ILLus 13 Plan of wall built on top of the bank of Period II; the bank was not visible, its stone face is shown for reference only 


\section{C: The first gravel wash (later Period V)}

In the topsoils of areas $B$ and $C$, and at the north-western edge of area $A$, was preserved clear evidence of water-scouring of the surfaces, and in places the complete removal of the topsoil and the erosion of the subsoil (illus 4 ). In area $A$ the southern edge of a channel eroded into the natural surface was found. Its extension downhill to the west was found in area $B$, though there, at the east end of the area, water channels had been formed only within the depth of the topsoil. Further to the west, the affected area broadened considerably and the topsoil was more extensively damaged, having been scoured off completely in the westernmost part of the area. Most of the width of area $\mathrm{C}$ was eroded to the level of the natural sand in the eastern part. To the west the water channel veered more to the south, leaving a relatively high bank at the north side of the trench which was hardly affected by the water flow. The water had cut a channel through the edge of the terrace. After the flow of water and the resultant erosions of the surfaces, water-borne gravel and sand deposits covered all of area $B$ to the west of the secondary wall, and most of area $C$, within the erosion channel. In area $A$ only the erosion channel in the corner was filled with gravel. The lenticulation of the gravel deposits would suggest that the burying of the site was not a single catastrophic event. Some fragmentary evidence of human activity on surfaces within the gravels also survived subsequent flooding and gravel deposition. At the west end of area $\mathrm{C}$, within the gravel, wood fragments preserved in waterlogged conditions were recovered. This material was made up of twigs, small branches and chips. A sample was submitted for radiocarbon dating (630 $\pm 60 \mathrm{bc}$; GU-1326).

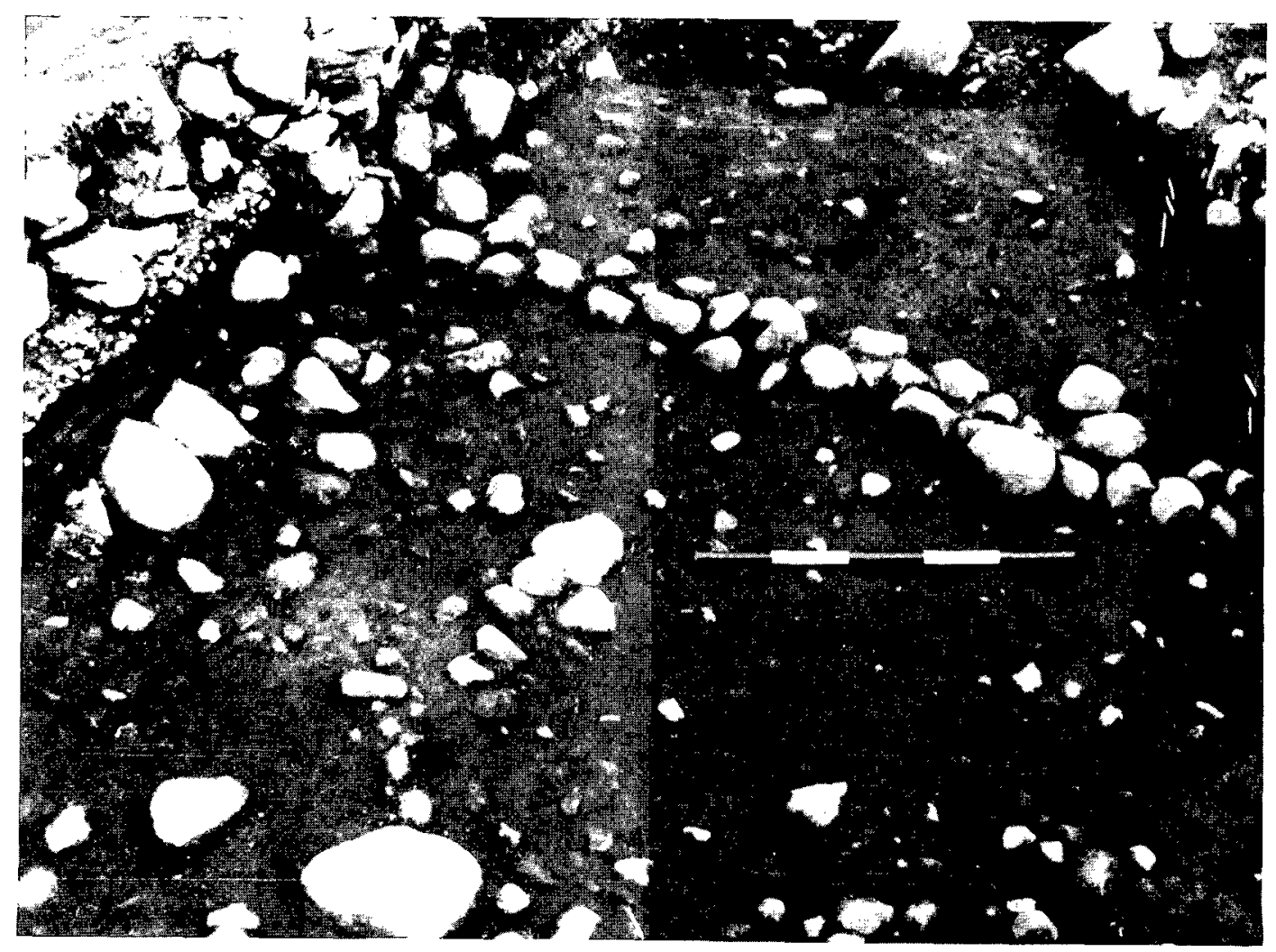

ILLuS 14 Line of stones possibly forming cultivation-plot boundary abutting the wall of Period V, from S 


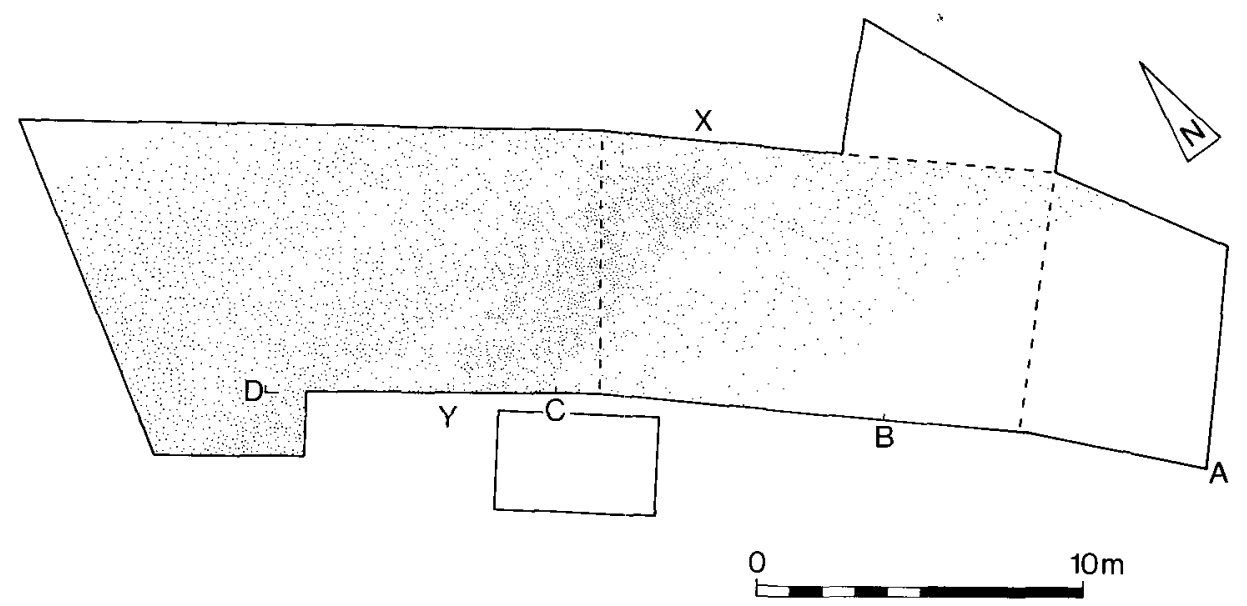

ILLuS 15 Areas affected by water scouring (the heavier stipple shows greater damage). The location of sections on illus 16 is shown

At the south-eastern edge of area B, along the line of the boundary bank, on its top, and along the edge of the erosion gully at the north of area $\mathrm{A}$, a low wall was built, after the gully was partly filled with gravel; this wall eventually collapsed. In area B the wall was partly buried by gravel prior to the Period VI activity.

In area $\mathrm{B}$ small erect stones were noted. One was placed in a hole at an early stage in the gravel deposition sequence. A similar stone was noted at a higher, later level in area $\mathrm{E}$, along with two stonepacked postholes (Period VI/VII). No associated surface had survived.

\section{D: Later settlement activity (Period VI)}

In the eastern part of the site, in area $A$ and the east part of B, was a dark charcoal-stained soil, thickest in $\mathrm{A}$ and thinning rapidly to the west in area $\mathrm{B}$ (illus $16 \& 17$ ). To the west, where the layer did not survive, the level of the hillwash surface was attested by a contemporary wall (wall 2) running from area B, where the layer survived, towards the west. This wall is described below. Stratigraphic evidence to sort the disparate feature groups of this Period into a chronological sequence is lacking. The order of the following descriptive paragraphs implies no chronological sequence. Refer to illus 17.

1 A group of 11 posts running from the south-eastern baulk of area A to the south corner of area B (numbered 1-11 on illus 17). A scatter of stakeholes may also be associated with this group.

2 A narrow groove c $3 \mathrm{~m}$ long, $10 \mathrm{~cm}$ broad and a maximum of $10 \mathrm{~cm}$ deep (labelled $12 \mathrm{on}$ illus 17). Small stones were set on edge across it throughout its length. They were spaced between $4 \mathrm{~cm}$ and $8 \mathrm{~cm}$ apart. It is likely that the groove and the stones supported a light fence.

3 A narrow drain defined by two lines of flat stones on edge with a coping, somewhat disturbed, of flat stones (labelled 19 on illus 17).

4 A single line of boulders (wall 2 on illus 17), one of which bore clear cupmarks, apparently beginning at the baulk forming the area A/area B boundary, though possibly running on from the still visible remnants of a wall of Period VI (labelled wall 3 on illus 17). Wall 2 ran to the west and left the excavated area at the southern corner of area $C$. Where first visible at the east, the wall was 0.56 m over site datum, at the west end it was $0.53 \mathrm{~m}$ below datum, running down the slope of the hillwash surface to the west. 

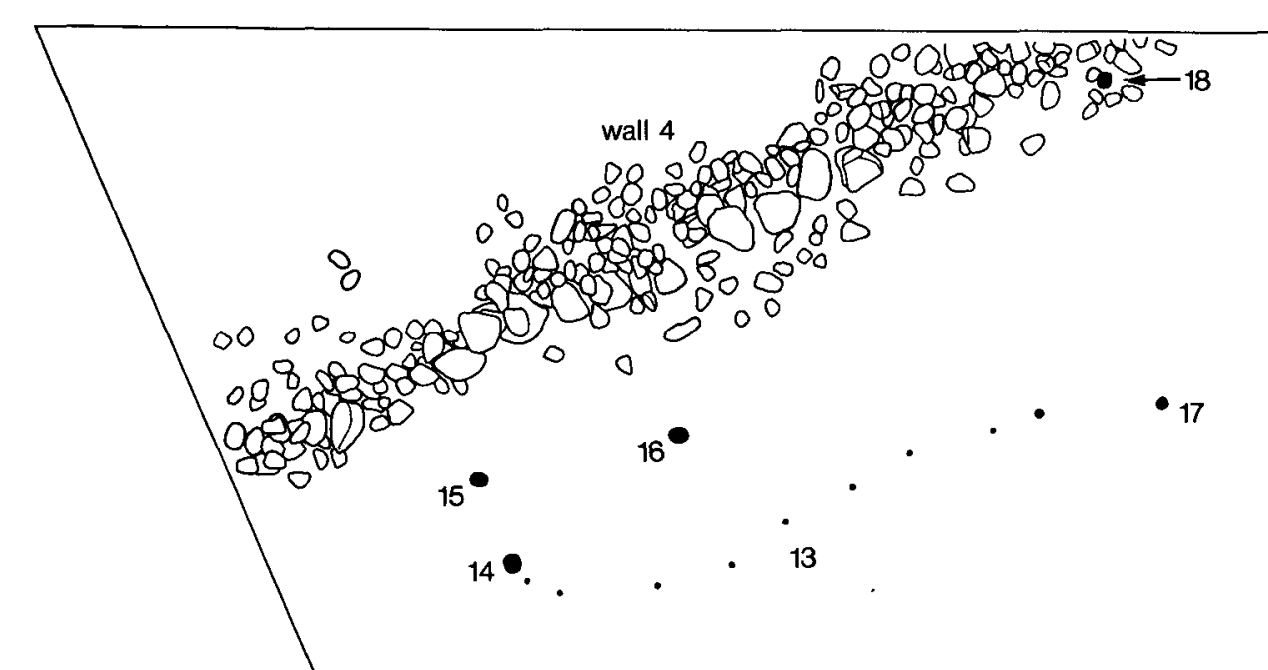
A

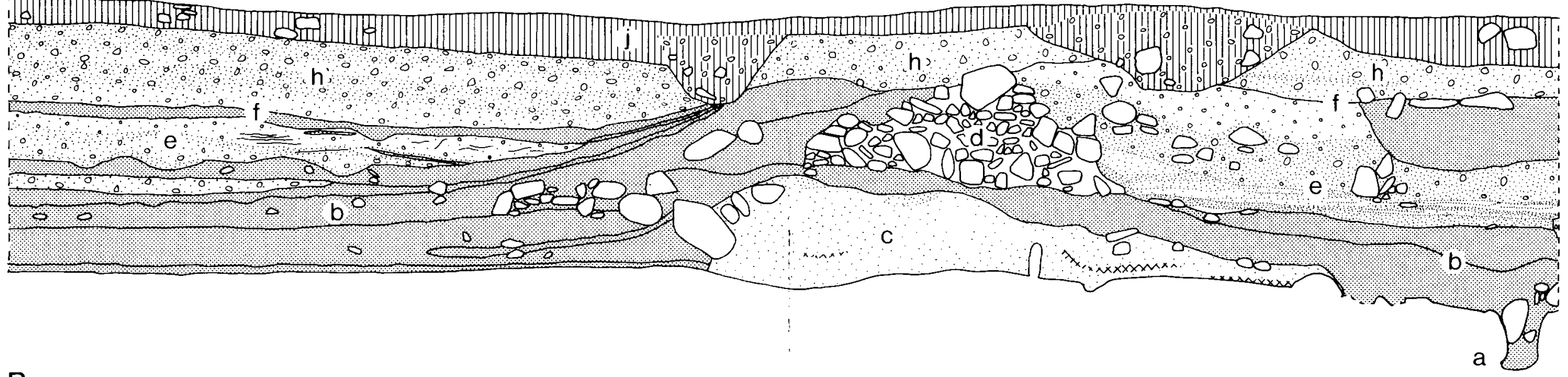

B

C

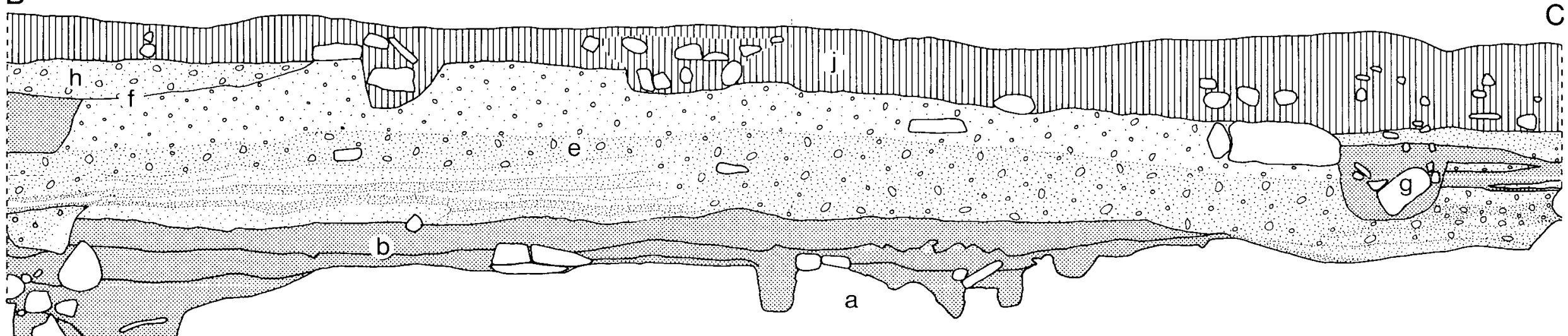

C

0

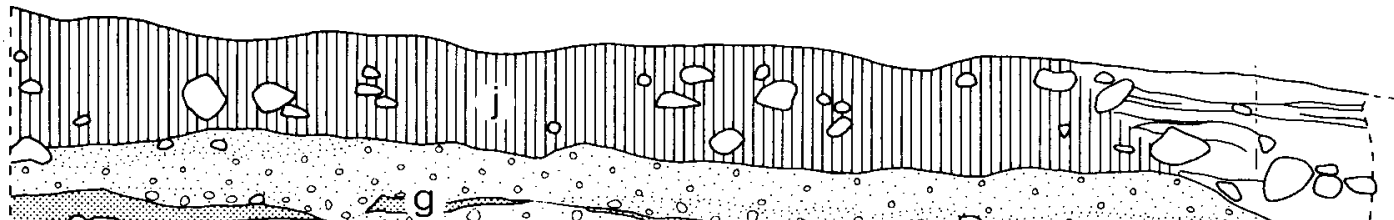

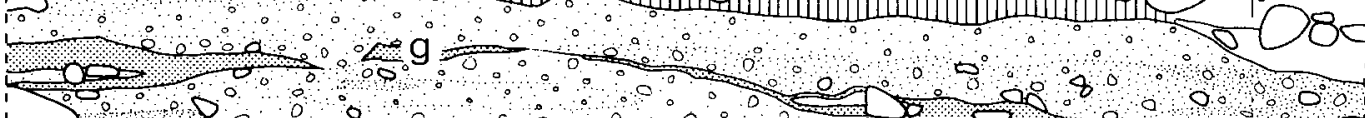

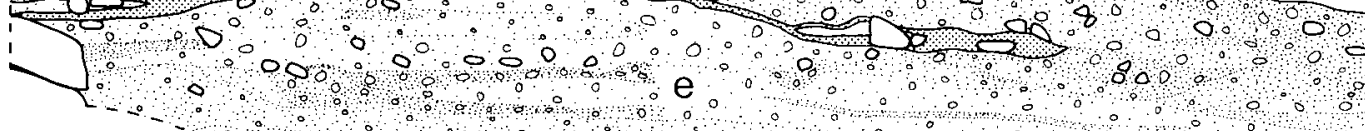

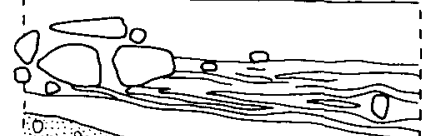

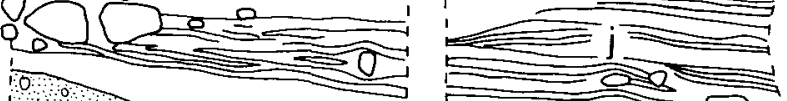

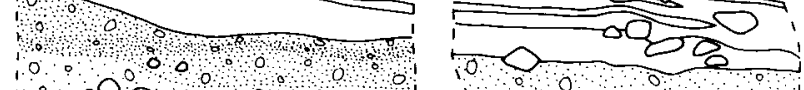
$\because 000 \% 00$ क 000 की

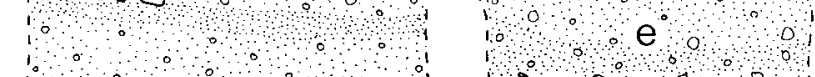
a) 0 r o

ILlus 16 Section along the site (location shown on illus 15). a subsoil; b agricultural and occupation soil of Periods I-V; $c$ primary settlement boundary: stone-faced bank (Period II) (separated by an agricultural soil from d); $d$ secondary settlement boundary wall (Period V); e material of first major gravel inundation (Later Period V); $f$ Period VI settlement layer; $g$ remains of occupation within gravels (Period VI/VII); h material of second major gravel inundation (Period VI/VII); j modern topsoil and sediment build-up 
To the north of wall 2 in area $C$ was a similar wall (labelled wall 4 on illus 17), though built with smaller stones. It lay on the north edge of the partly gravel-filled erosion channel.

In the gravel in area $C$, in what would have been the water channel, were nine small stakeholes arranged in a sinuous line (labelled 13 on illus 17) and four larger stakeholes (labelled 14-17). An isolated posthole lay to the east (18).

The features described in paragraphs $2,3,4,5$ and 6 above were poorly related to the sequence because of the erosion of occupation surfaces by water action. In the southern part of area $A$ there was clear evidence of sporadic water flow after and, perhaps, during the activity associated with the postholes. A shallow linear hollow formed by water action was later filled with alternate lenses of sand/silt and dark topsoil/occupation material.

\section{E: The second gravel wash (Period VI/VII)}

The gravel layers which covered the Period VI settlement activity extended further than the flow of Period V. The wash completely covered area A, hitherto only slightly affected, area B and all of area $C$ with the exception of the relatively high ground at the north edge. Area $D$ remained unaffected. The gravel covered the remnants of wall 3, wall 2 in area B and its paired wall, 4, in C, collapsing it in the process; all three walls had been built along the edges of the earlier water channel. Within the gravels were lenses of dark loam, limited in extent and associated on occasion with pottery

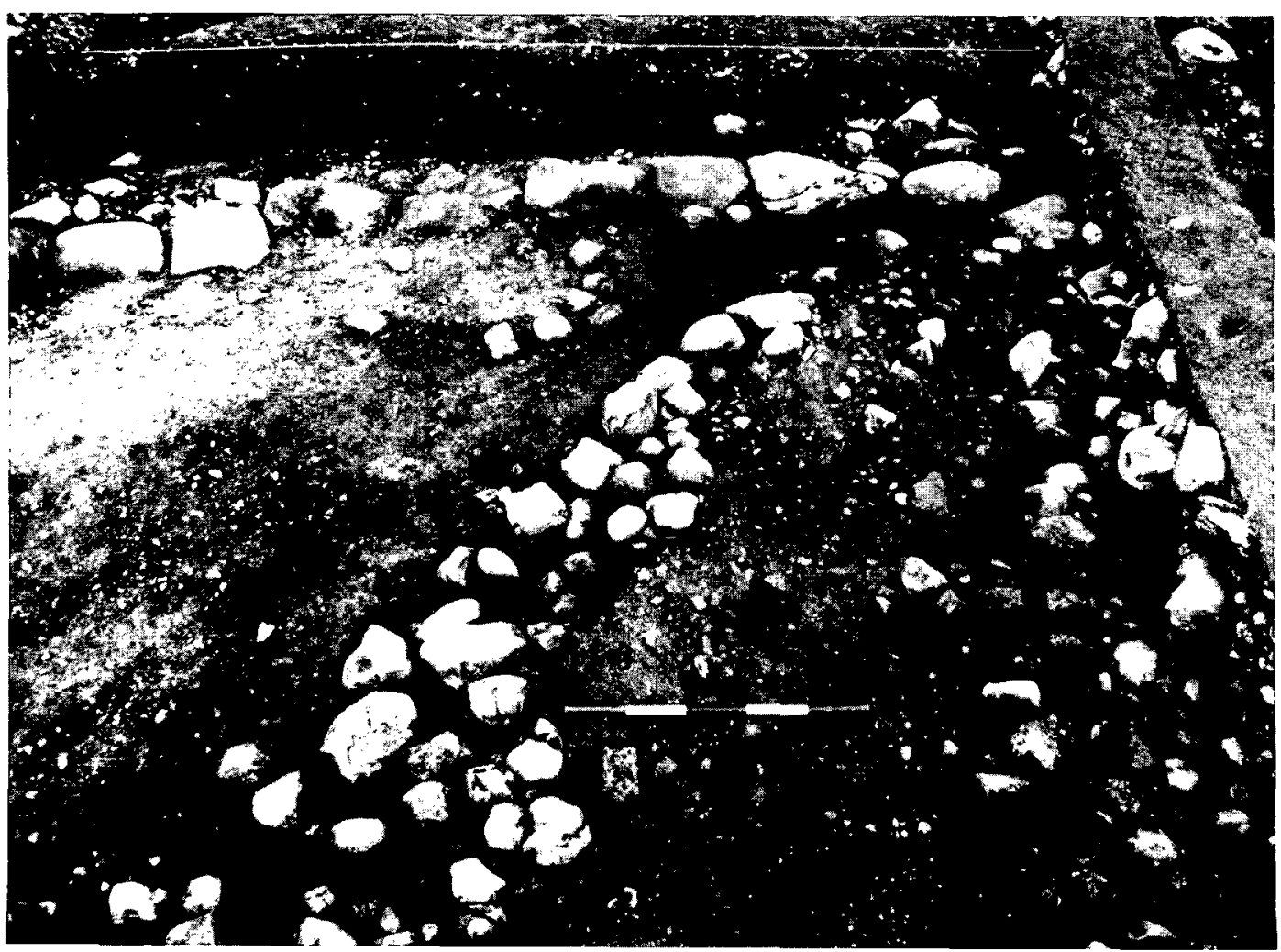

ILLUS 18 Walls 2 and 3 and feature 12, from SW 
and small pits (illus 16, g). There was clear evidence in area B that episodes of water scouring had alternated with periods of gravel deposition.

It is suggested that the loam layers represent episodes of stabilization within the upper gravel deposits, damaged by subsequent water flow and deposition. Pits dug into the hillwash and scatters of artefacts are all that survive.

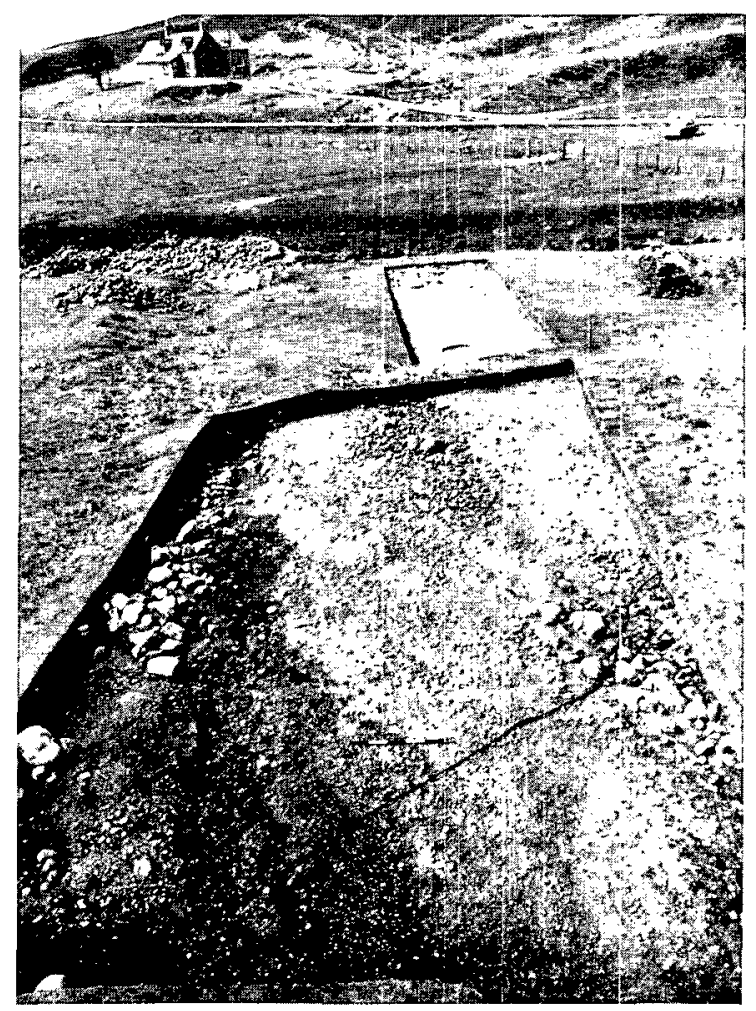

ILLus 19 The north-western end of the site showing the surface of the gravel inundation

\section{F: The souterrains}

Three souterrains now bear the name 'Suisgill'; one was recorded by the RCAMS in 1911 (Suisgill I), one (Suisgill II) lay immediately by the A897 at the site of the excavation and the last (Suisgill III) was discovered during test digging for the realigned A897, as described earlier (illus 20).

\section{Suisgill I}

'On a level meadow . . . are the remains of an earth-house. Neither extremity is open, and at two places the roofing slabs have been removed so that the interior is largely filled up with earth and stones. The passage is visible for a distance of $24^{\prime}(\mathrm{c} 7.3 \mathrm{~m})$, curving round so as to give a chord of 19' (c $5.8 \mathrm{~m}$ ) between the extremities on the inner side. The sides are built and the roof formed of slabs. The passage is $2^{\prime} 6^{\prime \prime}(\mathrm{c} 0.75 \mathrm{~m})$ and $2^{\prime} 8^{\prime \prime}(\mathrm{c} 0.8 \mathrm{~m})$ wide respectively at the extremities, and $3^{\prime}$ (c $0.9 \mathrm{~m}$ ) wide where unroofed near the middle of its course' (RCAMS 1911, no 342). 

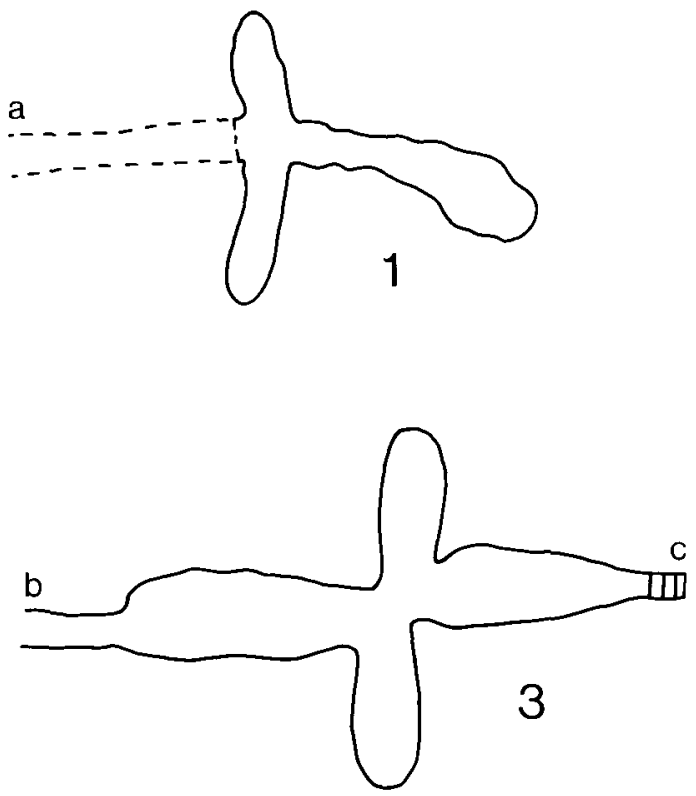
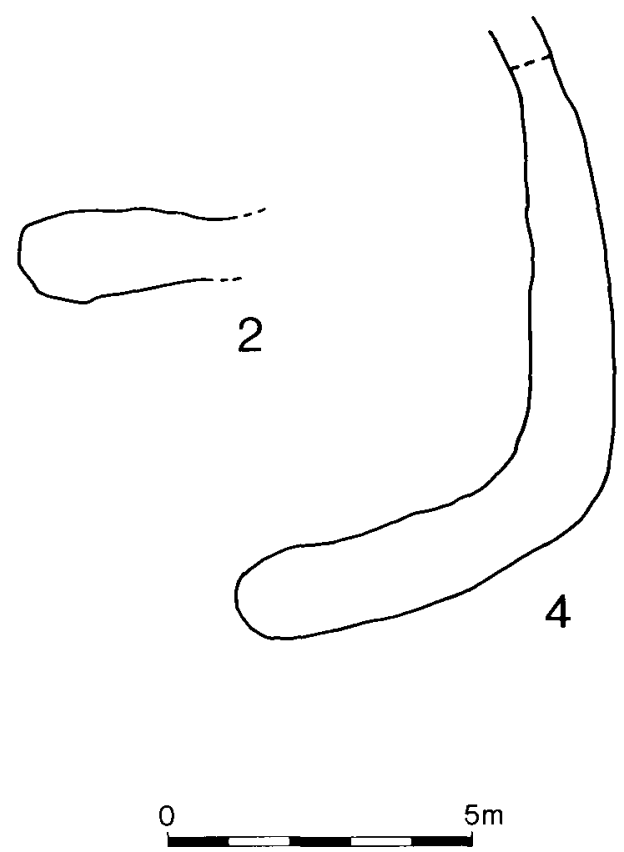

ILLUS 20 Plans of souterrains: 1, Suisgill III, 2, Suisgill II; 3, Kirkton, Golspie; 4, Achinnearin

\section{Suisgill II}

This passage survives to a maximum length of $3.6 \mathrm{~m}$ and appears to be the inner end of a longer souterrain, the remainder of which has been destroyed by the building of the modern road. It is between $0.95 \mathrm{~m}$ and $1.45 \mathrm{~m}$ broad and survives to a maximum of $1.3 \mathrm{~m}$ high, though modern infill has certainly reduced this. The passage is built of drystone blocks and has a slab roof. In the rear wall (illus 21 ) is a deliberately built alcove approximately $0.45 \mathrm{~m}$ square. No excavation was undertaken in this structure.

\section{Suisgill III}

During the excavation of the settlement, the machine pit which had revealed the souterrain was re-excavated. An area $5 \mathrm{~m}$ by $6 \mathrm{~m}$ was opened over the passage. Once the roof of the passage was revealed it was decided that one of roofing slabs should be removed to allow access into the soil-free space below. The souterrain was cruciform in shape; entry during the excavation was gained through the roof of the north-west side-passage. A similar side passage extended to the south-east. From the junction two further passages extended; one, broadening and curving slightly to the north was the main chamber (illus $22 \& 23$ ). The other, completely soil-filled, its roof slabs rising to the surface to the west, was apparently the entrance. Sterile loam, largely introduced through the entrance, had filled all the chambers to some extent. The entrance passage was completely blocked. From the junction of the passages the fill sloped down into the three subsidiary chambers; the two side chambers were filled to within $50 \mathrm{~cm}$ of their roofs; the main chamber was filled to any great depth only near its entrance. Elsewhere in the main chamber probing showed a fill only $30 \mathrm{~cm}$ deep. A proportion of the fill had found its way through the wall of the souterrain by water percolation and the activities of rodents and roots. At the level of the top of the fill, the side passage measured between $60 \mathrm{~cm}$ and $80 \mathrm{~cm}$ broad. The north-west passage was $2.45 \mathrm{~m}$ long, the southeast passage measured $1.8 \mathrm{~m}$ long from the intersection. However, the passages were clearly broadening rapidly towards their bottom. The main chamber measured approximately $4.5 \mathrm{~m}$ from the intersection and was a maximum of $1.4 \mathrm{~m}$ high; as noted above, this chamber was a further $30 \mathrm{~cm}$ deep in soil fill. The entrance passage was approximately $60 \mathrm{~cm}$ across at the intersection; traces of this passage on the surface 


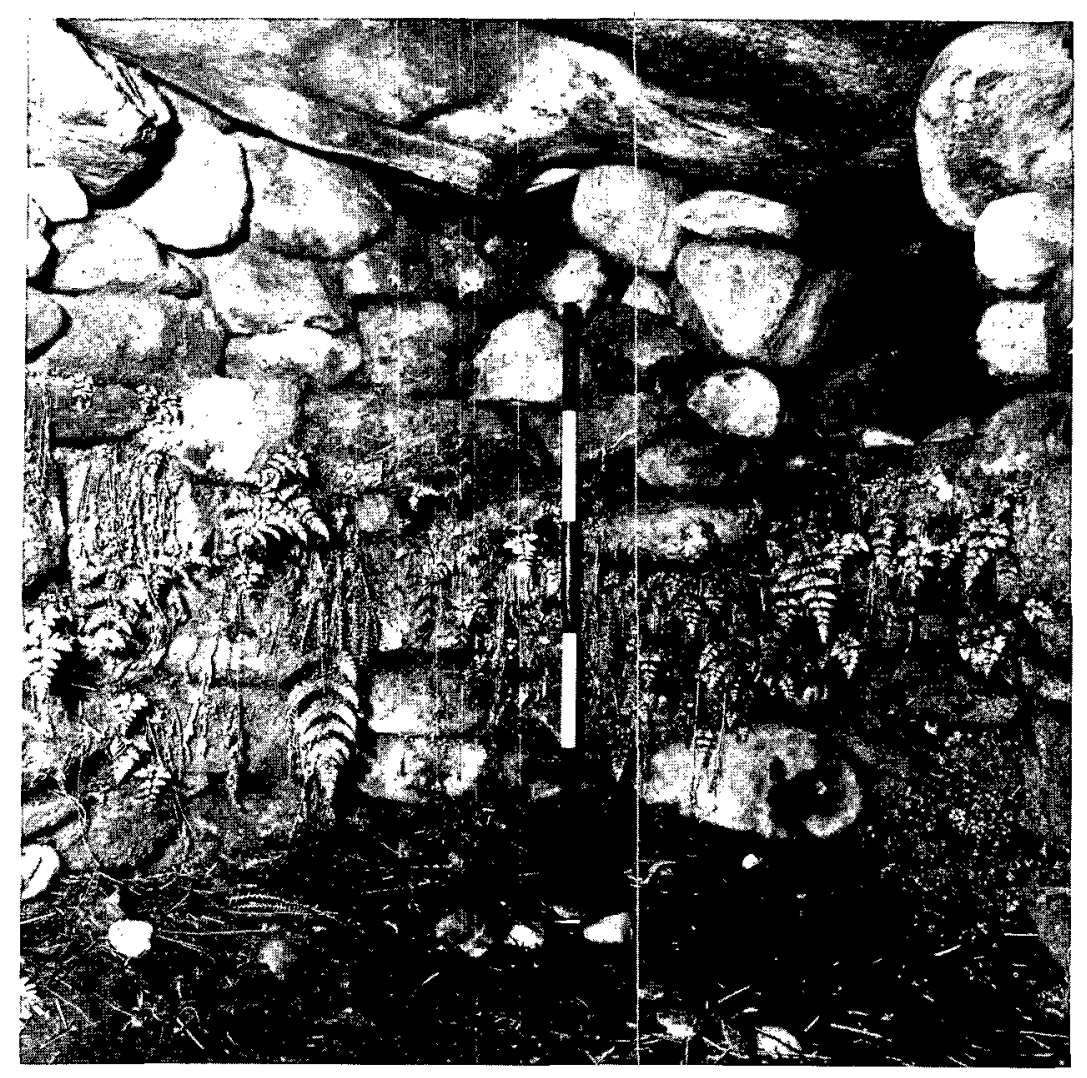

ILLUS 21 Interior of souterrain Suisgill II, showing 'alcove'

were noted for $4 \mathrm{~m}$ to the north (illus 24 ). The structure was built of slabs and blocks topped by very large roofing slabs; the main chamber was almost entirely roofed by two slabs.

On the surface two features were noted. The roof and wall-tops of the entrance passage have been mentioned above. The entrance passage led towards the eastern corner of the trench where, to the northwest, a line of stones, perhaps the remnants of a low wall, were found. It is possible that a stone-walled hut associated with the souterrain is represented by this feature. A charcoal sample was recovered from a small sondage dug through the shallow fill of the main chamber; unfortunately the radiocarbon assay obtained had a standard deviation too large to be of use.

\section{G: Recent occupation}

There were two fragments of recent buildings on the site; they survived to a maximum of two courses high. The northern one (A on illus 25) survived as a corner only, where the east and south walls met. Immediately to the south-east were the more completely preserved remains of a rectangular building (B on illus 25): the whole length of the west and south walls survived and parts of the north and east walls are also present. The north-east corner had been removed. The second building would have measured $3.5 \mathrm{~m}$ by $4.5 \mathrm{~m}$ when complete. No internal features were noted. It is suggested that the smaller fragment (A) represented the remains of a building, superseded by (B). The destruction of the northern parts of both buildings seems to have been associated with the construction of the original gravel road which had descended to the ford to the north-west of the site. A halfpenny of George III (1806) was found in the fill of the more complete building. To the west of the structures was a slightly sunken stone-edged path (C on illus 25 ), possibly associated with the buildings. The buildings were almost certainly part of the pre-improve- 


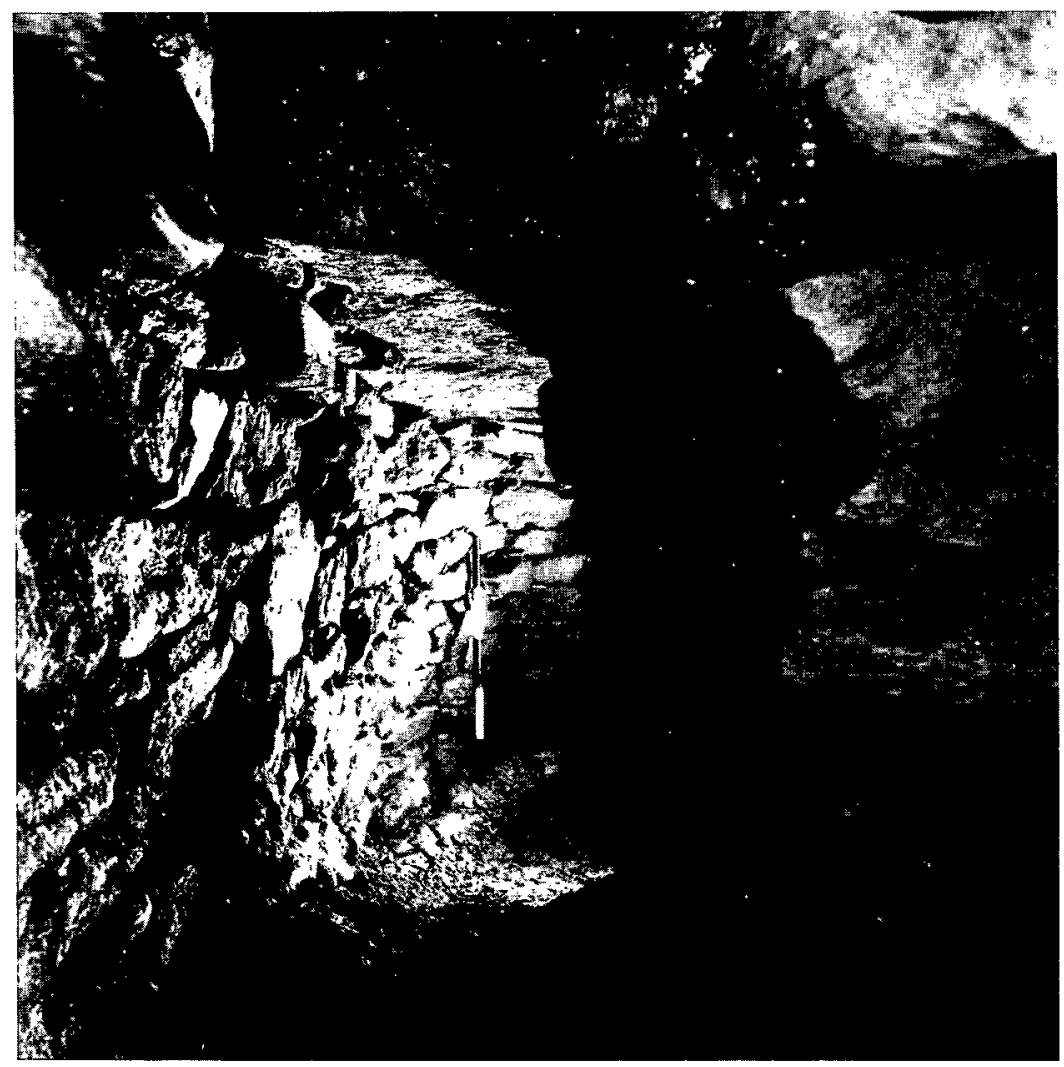

ILLUS 22 Interior of souterrain Suisgill III, looking from the intersection of the passages into the main chamber

ment settlement of buildings and a corn-drying kiln which lies between the excavation and the 'dun' (illus $1)$.

At the west of area B a small trench was opened in the second season. The upper part of the deposits (the trench was not taken to bottom) were very disturbed. Areas of burning occupying a rough scoop produced pottery of the post-medieval period. No clue to the activities represented by these deposits was found.

\section{2: POTTERY}

\section{J A Lee and G J Barclay}

\section{DESCRIPTION}

The pottery assemblage was sorted into 10 fabric groups by Lee (table 1) and subsequently sorted into a number of stylistic groups. The great majority of the sherds fall into five of the fabric groups (A1, A2, $\mathrm{B}, \mathrm{C}$ and D). A1 is found in deposits of Periods I to III (early first millennium bc); A2 occurs in Periods I to IV (early first millennium bc); B appears in Periods IV to VI (early to mid/late first millennium bc); and C appears in Periods V and VI (mid to late first millennium bc). Fabric D is post-prehistoric (Period VII). The other fabric groups are distributed as follows: $\mathrm{A} 3$ and $\mathrm{H}$-Periods I to III; F and G-Period VI; E- two 


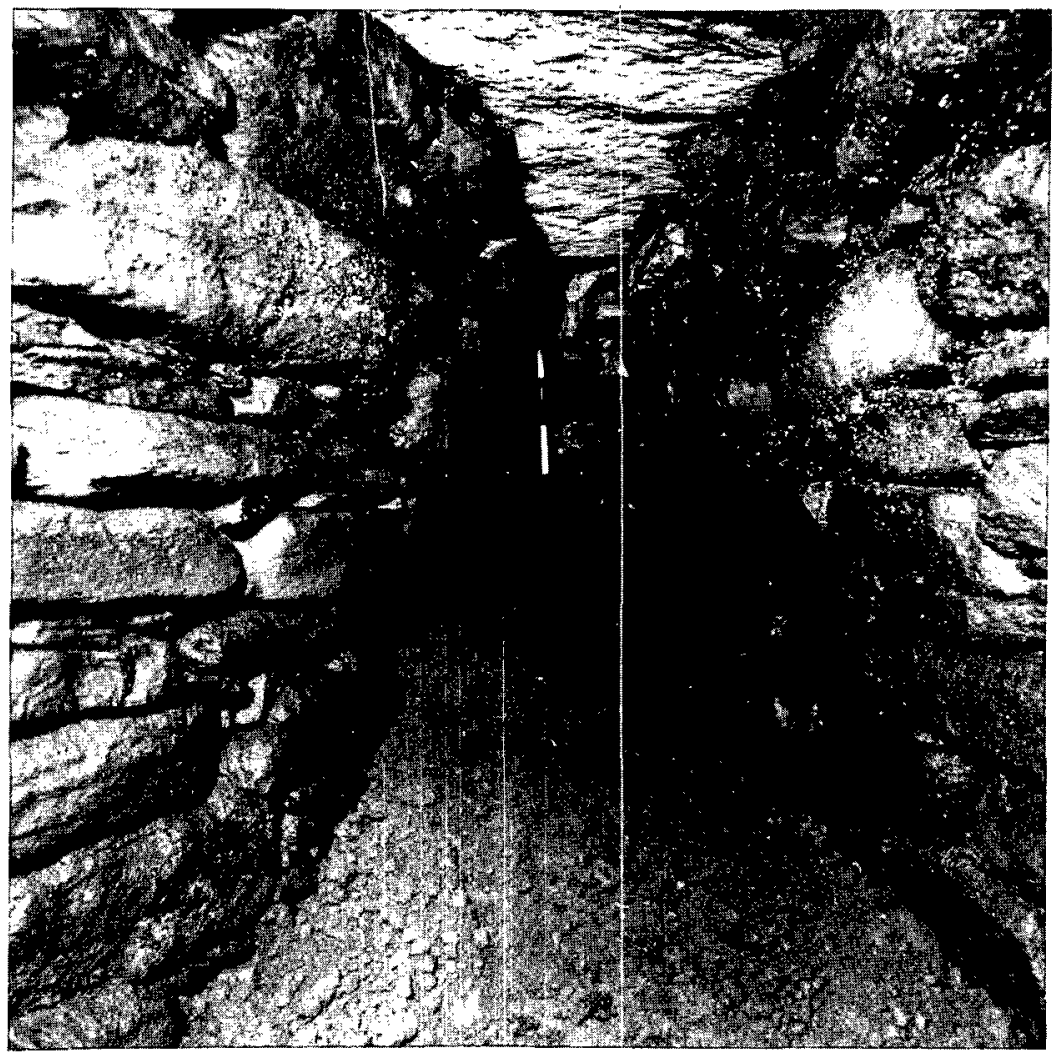

ILLUS 23 Interior of souterrain Suisgill III, looking from the main chamber towards the intersection of the passages

joining sherds, one found in Period I, the other in Period V context (illustrating the pitfalls of the process as far as small assemblages are concerned and the problems posed by water-worked deposits).

There are three main stylistic groups:

1 flat-rimmed steep-sided vessels,

2 a variety of vessels with splayed rims or with internally steeply sloping rims,

3 vessels with everted rims, and more or less constricted necks.

The majority of flat-rimmed vessels were of fabric A2. A single flat rim in fabric $\mathrm{C}$ has, perhaps, more in common with the splayed rims. The single very narrow rim of fabric $\mathrm{H}$ is likewise not really comparable with the A2 examples. The second group of rims, possibly from shallow bowls, were found in fabric groups A2, $(S F 2, S F 6), \mathrm{A} 3(S F 9), \mathrm{B}(S F 14, S F 15)$, and C (SF22). The everted rims were largely associated with fabric B, though similar forms appear in fabric C. Bases $S F 19$ and $S F 20$ of fabric B may be from the same form of vessel.

Generally the stylistic groups were dated thus:

1 Group Periods I to IV (early to mid first millennium bc),

2 Group Periods I to VI (most of first millennium bc),

3 Group Period IV to VI (mid to late first millennium bc). 


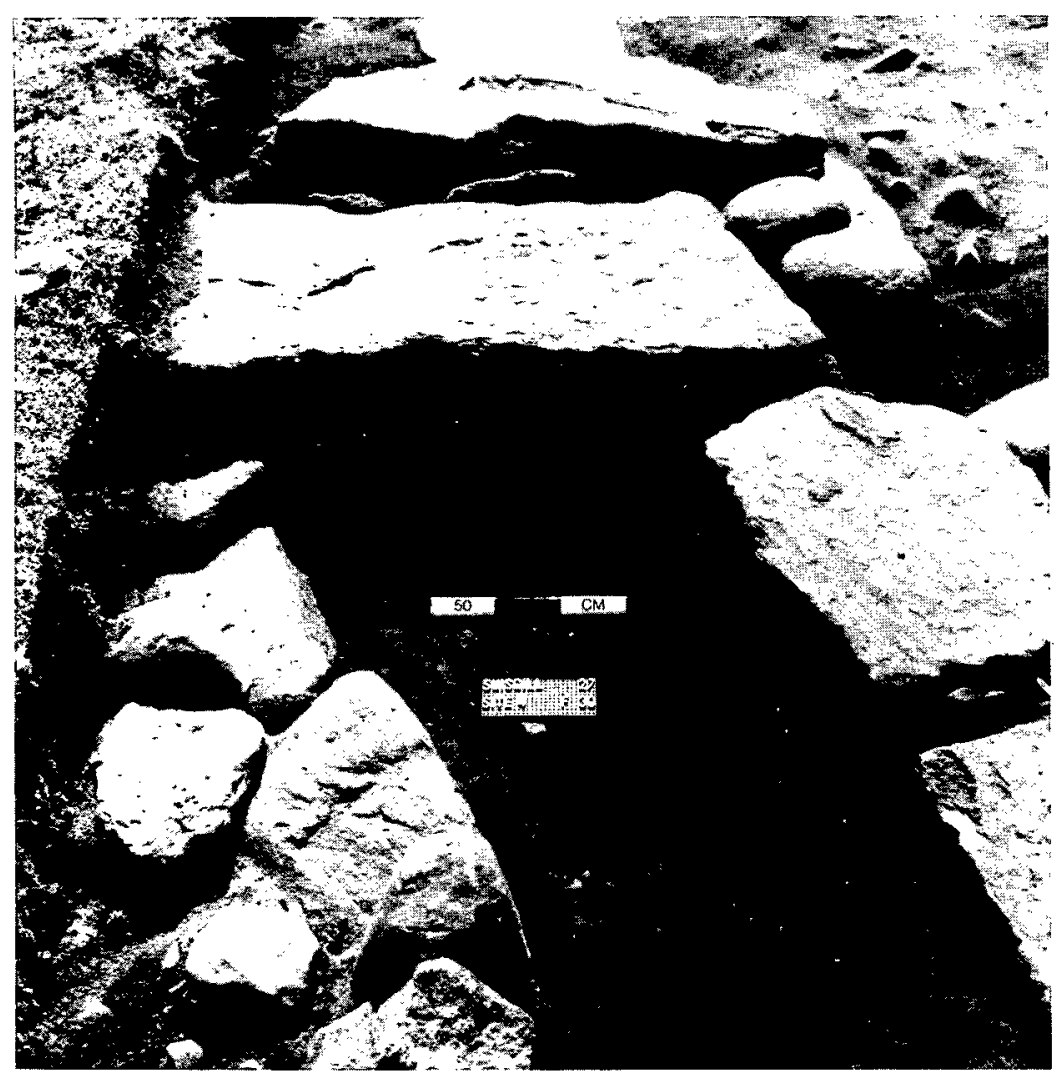

ILLus 24 The entrance passage of Suisgill III at the surface

TABLE 1

Summary of pottery fabrics $(E=$ exterior, $I=$ interior, $C=$ core $)$

Total

Weight

Group (g)

Brief Description

A1 $\quad 54$

A2 676

A3 12

B 2429

C $\quad 871$

D $\quad 164$

E $\quad 103$

F $\quad 28$

G $\quad 21$

Hard, rough, uneven fracture, ill-sorted inclusions (mica schist), E; pinkish grey; I+C: very dark grey.

Soft, smooth, uneven fracture, better sorted inclusions (mica schist), E+C: light grey, light brown; I: dark grey.

Soapy (steatite), E: dark grey, pinkish grey; I+C: dark grey.

Soft, rough, very uneven fracture, ill sorted (igneous), $E+C$ : light reddish brown, brown, reddish brown; I: greyish brown, brown.

Soft, rough, uneven fracture, ill sorted (igneous), I+E $+\mathrm{C}$ : very pale brown, pale brown, light yellowish brown.

Hard, very rough, even fracture, well sorted (mica, quartz, igneous), E+I: brown, C: dark grey.

Soft, rough, uneven fracture, grog tempered, E: pale yellowish brown, very dark grey; I: greyish brown; C: brown.

Soft, smooth, laminated fracture, ill sorted, linear voids, E: dark brown, I: dark greyish brown; C: greyish brown.

Hard, smooth, uneven fracture, E: very dark greyish brown (burnished); I+C: black.

70 Hard, smooth, uneven fracture, cork-like appearance, E: pale brown: I: greyish brown, black; $\mathrm{C}$ : dark brown, dark greyish brown. 


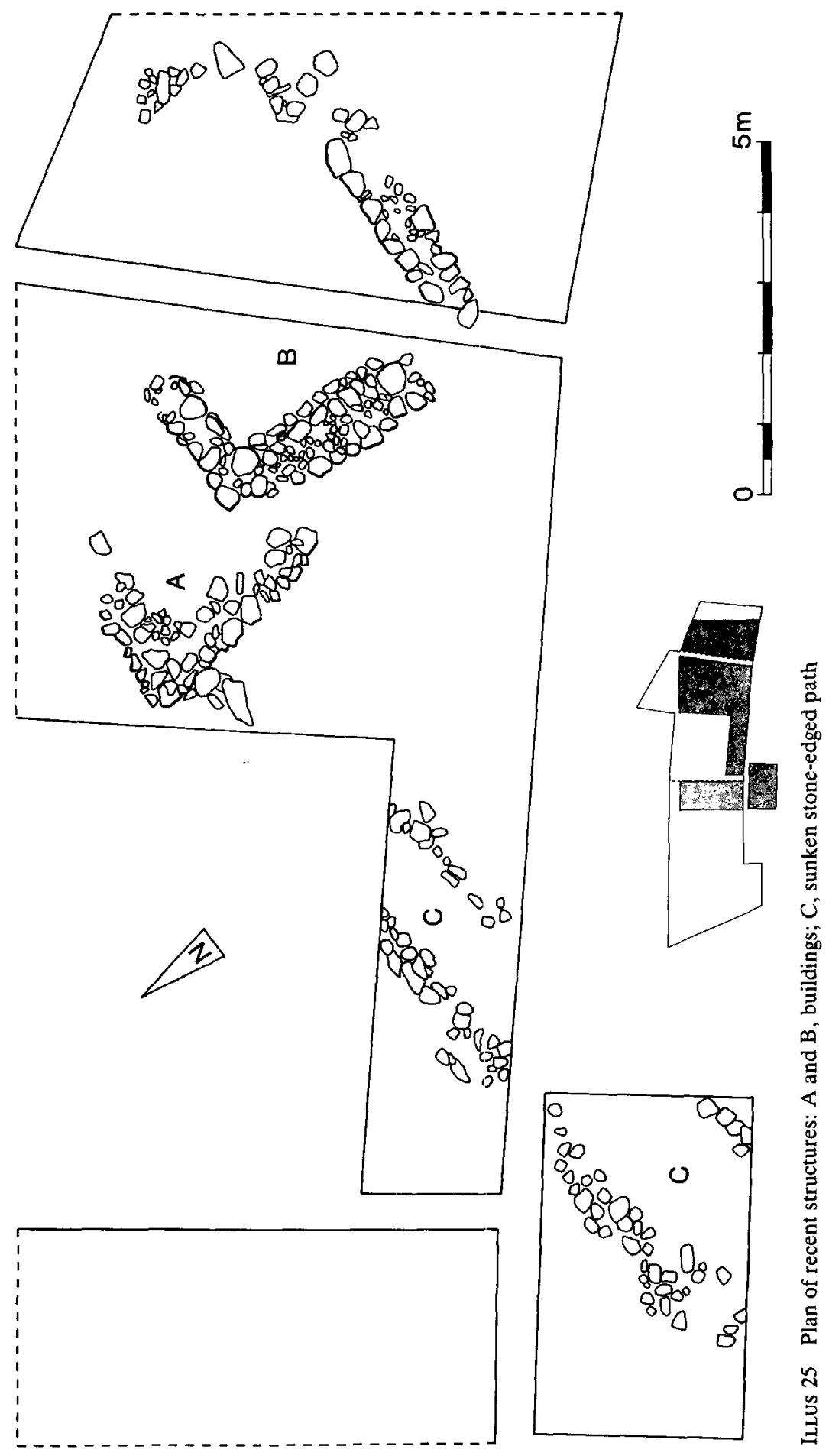


A pattern of gradual change from flat to more everted rims can be seen in the mid first millennium bc.

Decoration is rare; the odd form which is the sole member of fabric group $\mathrm{E}$ is unusual in having a lug. A single piece formed of two sherds ( $S F 10$; fabric B) has finger impressions below the rim. $S F 13$ has what may be grass impressions below the rim.

\section{CATALOGUE OF RIM AND BASE SHERDS}

It was felt that there was no value in publishing a complete pottery catalogue as most of the material was uninformative. Only the rims and bases have been listed, by fabric and by period. All are illustrated in illus 28 and 29.

\begin{tabular}{|c|c|c|c|c|}
\hline Fabric & SF no & Period & Type & Description \\
\hline A1 & SF1 & I-III & Rim & $\begin{array}{l}\text { Abraded, especially on top of rim, may show use of stone } \\
\text { lid; appears to be slightly everted. }\end{array}$ \\
\hline \multirow[t]{7}{*}{ A2 } & SF2 & I-III & Rim & Flattened rim with internal flange. \\
\hline & SF3 & II-IV & Rim & Slightly inturned, rounded at top with internal thickening. \\
\hline & SF4 & II-IV & Rim & Flat direct rim widening towards top on both sides. \\
\hline & SF5 & IV/V & Rim & Flattened upright with slight thickening on external wall. \\
\hline & SF6 & $\mathrm{V}$ & Rim & $\begin{array}{l}\text { Flat top with thickening on both sides, especially exterior } \\
\text { wall. }\end{array}$ \\
\hline & SF7 & I-III & Base & $\begin{array}{l}\text { Flat bottomed; thickening where base joins wall; wall } \\
\text { leaves base at an exterior angle of } 90^{\circ} \text {. }\end{array}$ \\
\hline & SF8 & II/III & Base & $\begin{array}{l}\text { Flat bottomed; protruding foot; wall leaves base at an } \\
\text { exterior angle of } 100^{\circ} \text {. }\end{array}$ \\
\hline A3 & SF9 & I-III & $\operatorname{Rim}$ & $\begin{array}{l}\text { Flat top with well defined exterior flange and some } \\
\text { thickening on interior wall. }\end{array}$ \\
\hline \multirow[t]{11}{*}{ B } & SF10 & IV $/ \mathrm{V}$ & $\operatorname{Rim}$ & $\begin{array}{l}\text { Sharply everted with finger marks on shoulder of main } \\
\text { part of pot. }\end{array}$ \\
\hline & SF11 & V & $\operatorname{Rim}$ & $\begin{array}{l}\text { Strongly everted; rounded top with finger marks below } \\
\text { rim. }\end{array}$ \\
\hline & SF12 & $\mathrm{V}$ & Rim & $\begin{array}{l}\text { Moderately everted with slight thickening on external } \\
\text { wall. }\end{array}$ \\
\hline & SF13 & V & Rim & Everted; incised lines just below rim. \\
\hline & SF14 & $\begin{array}{l}\text { VI/ } \\
\text { disturbed }\end{array}$ & Rim & Slightly everted and flattened; possibly shallow bowl. \\
\hline & SF15 & VII & $\operatorname{Rim}$ & Everted rim of a shallow vessel. \\
\hline & SF16 & VII & Rims & $\begin{array}{l}\text { Four rims from the same vessel; all everted to some } \\
\text { degree. }\end{array}$ \\
\hline & SF17 & IV/V & $\operatorname{Rim}$ & $\begin{array}{l}\text { Slightly everted, external thickening; finger marks just } \\
\text { below rim. }\end{array}$ \\
\hline & SF18 & IV/V & $\operatorname{Rim}$ & Similar to SF17. \\
\hline & SF19 & V & Base & $\begin{array}{l}\text { Flat bottomed; slight protruding foot; wall leaves base at } \\
\text { exterior angle of } 100^{\circ} \text {. }\end{array}$ \\
\hline & SF20 & $\begin{array}{l}\text { VI/ } \\
\text { disturbed }\end{array}$ & Base & $\begin{array}{l}\text { Flat bottomed; thickening on exterior wall where it meets } \\
\text { base; wall leaves base at exterior angle of } 100^{\circ} \text {. }\end{array}$ \\
\hline \multirow[t]{5}{*}{ C } & SF21 & $\mathrm{I}-\mathrm{V}$ & Rim & \\
\hline & SF22 & III/IV & Rim & Flattened top, sharply out-turned. \\
\hline & SF23 & V & $\operatorname{Rim}$ & Sharply everted; narrower than rest of body. \\
\hline & SF24 & III/IV & Base & Flat bottomed; wall leaves base at exterior angle of $95^{\circ}$. \\
\hline & $\begin{array}{l}\text { SF25 } \\
\text { SF26 }\end{array}$ & V & Base & Flat bottomed; wall leaves base at an exterior angle of $95^{\circ}$. \\
\hline $\mathrm{E}$ & SF27 & $\mathrm{I}-\mathrm{V}$ & $\operatorname{Rim}$ & $\begin{array}{l}\text { Slightly everted rim; broad channel above shoulder on } \\
\text { exterior; flattened lug below shoulder. }\end{array}$ \\
\hline $\mathrm{H}$ & SF28 & I-III & $\operatorname{Rim}$ & Narrow direct rim with rounded top. \\
\hline $\begin{array}{l}\text { Not } \\
\text { grouped }\end{array}$ & SF29 & I-III & Rim & Simple straight sides, flat top. \\
\hline
\end{tabular}




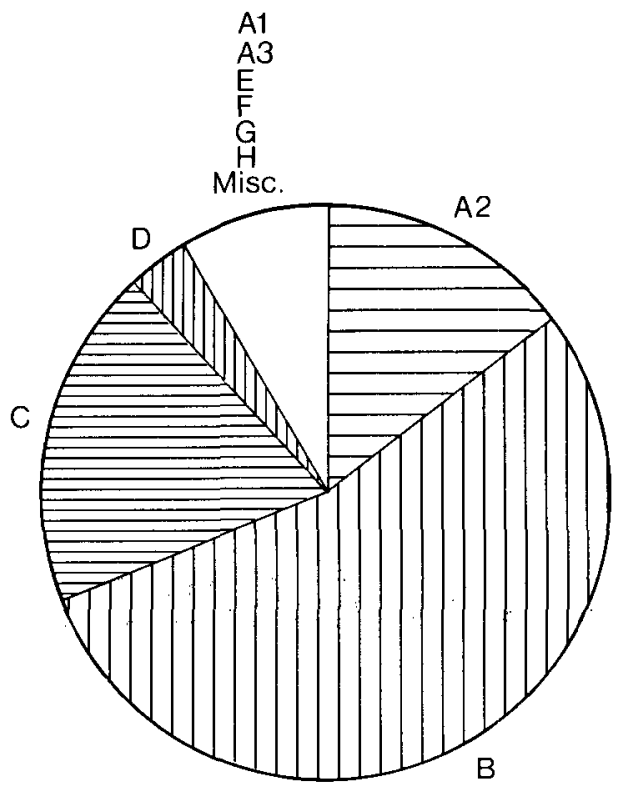

ILLus 26 Pie chart showing proportion of fabric types forming the assemblage

\section{3: STONE ARTEFACTS}

\section{SHALE BRACELETS}

SF30 A fragment of a bracelet originally c $60 \mathrm{~mm}$ in diameter (internal). It survives to $12 \mathrm{~mm}$ across and the same thick. The cross-section is not intact.

SF31 A fragment of a bracelet originally c $54 \mathrm{~mm}$ in diameter (internal). The cross-section is intact, and measures $11 \mathrm{~mm}$ across and $10 \mathrm{~mm}$ thick.

SF32 A fragment of a bracelet originally c $48 \mathrm{~mm}$ in diameter (internal). The cross-section is not intact. It survives to a maximum of $14 \mathrm{~mm}$ across and $7 \mathrm{~mm}$ thick.

All three bracelets were found in late/disturbed contexts and cannot therefore be tied into the site sequence.

\section{QUERNS}

SF33 An intact saddle quern measuring $545 \mathrm{~mm}$ by $355 \mathrm{~mm}$ and $120 \mathrm{~mm}$ deep. The top surface is smoothed and dished. This quern lay in disturbed occupation material and dates from the span of Periods I to III.

SF34 An intact saddle quern measuring $625 \mathrm{~mm}$ by $417 \mathrm{~mm}$ and $86 \mathrm{~mm}$ deep. The top surface is smoothed and heavily dished. This quern lay over a posthole of Period II and probably belongs to Period III.

SF35 An intact saddle quern measuring $413 \mathrm{~mm}$ by $250 \mathrm{~mm}$ and $97 \mathrm{~mm}$ deep. The working surface is slightly dished. Although it shows signs of wear, it still retains the peck marks produced in creating the surface; it had therefore not been in use for long. This quern was reused as packing in a posthole of Period II (House 1a).

SF36 An irregular boulder fragment $255 \mathrm{~mm}$ by $225 \mathrm{~mm}$ and c $145 \mathrm{~mm}$ deep. The top face is smoothed and slightly dished. It appears to be a fragment of a quern. This piece was found in the wall on top of the primary boundary bank (Period V) and therefore was deposited in Period VI. 

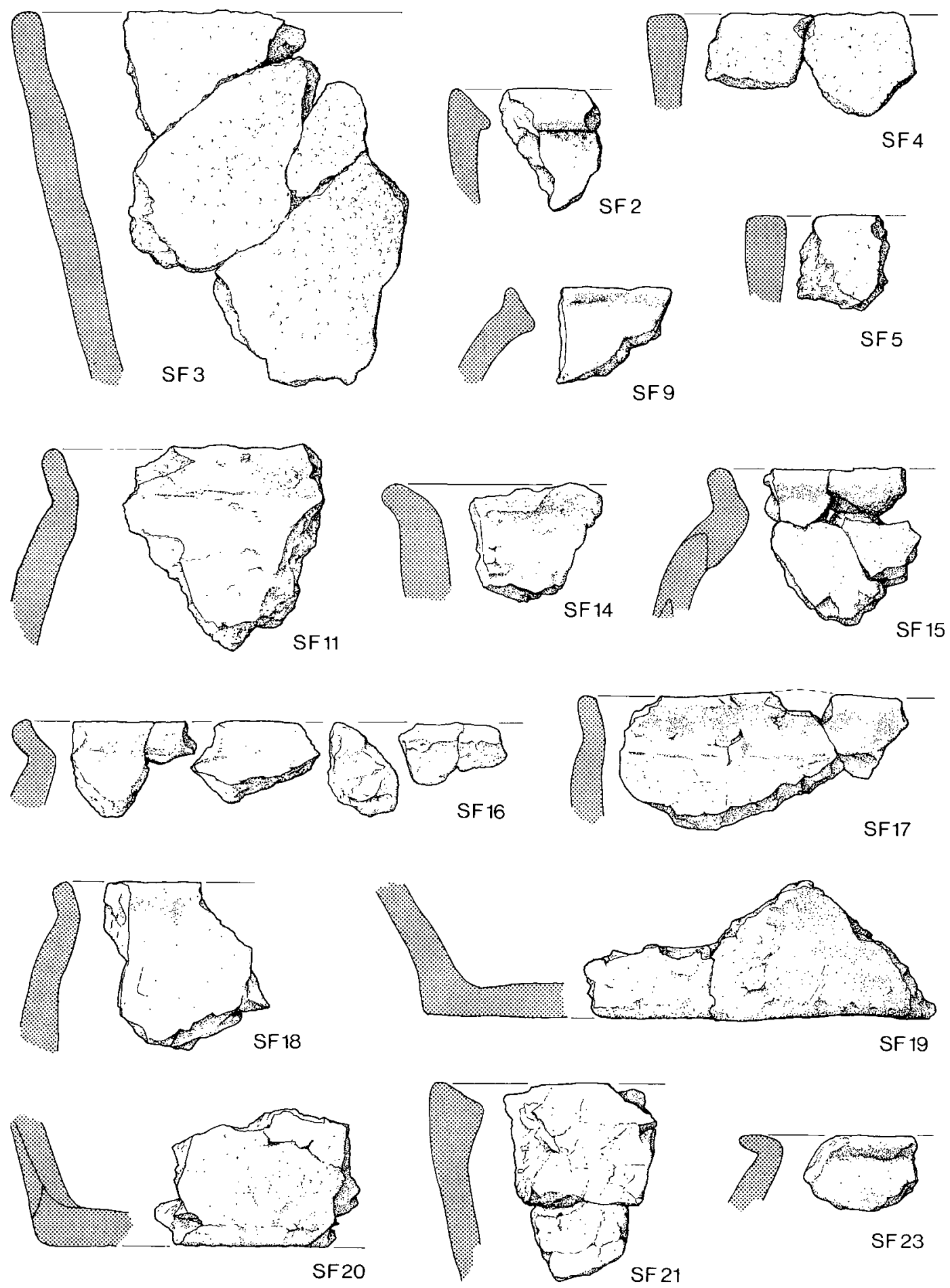

ILLus 27 Pottery (scale 1:2) 
186 | SOCIETY OF ANTIQUARIES OF SCOTLAND, 1985
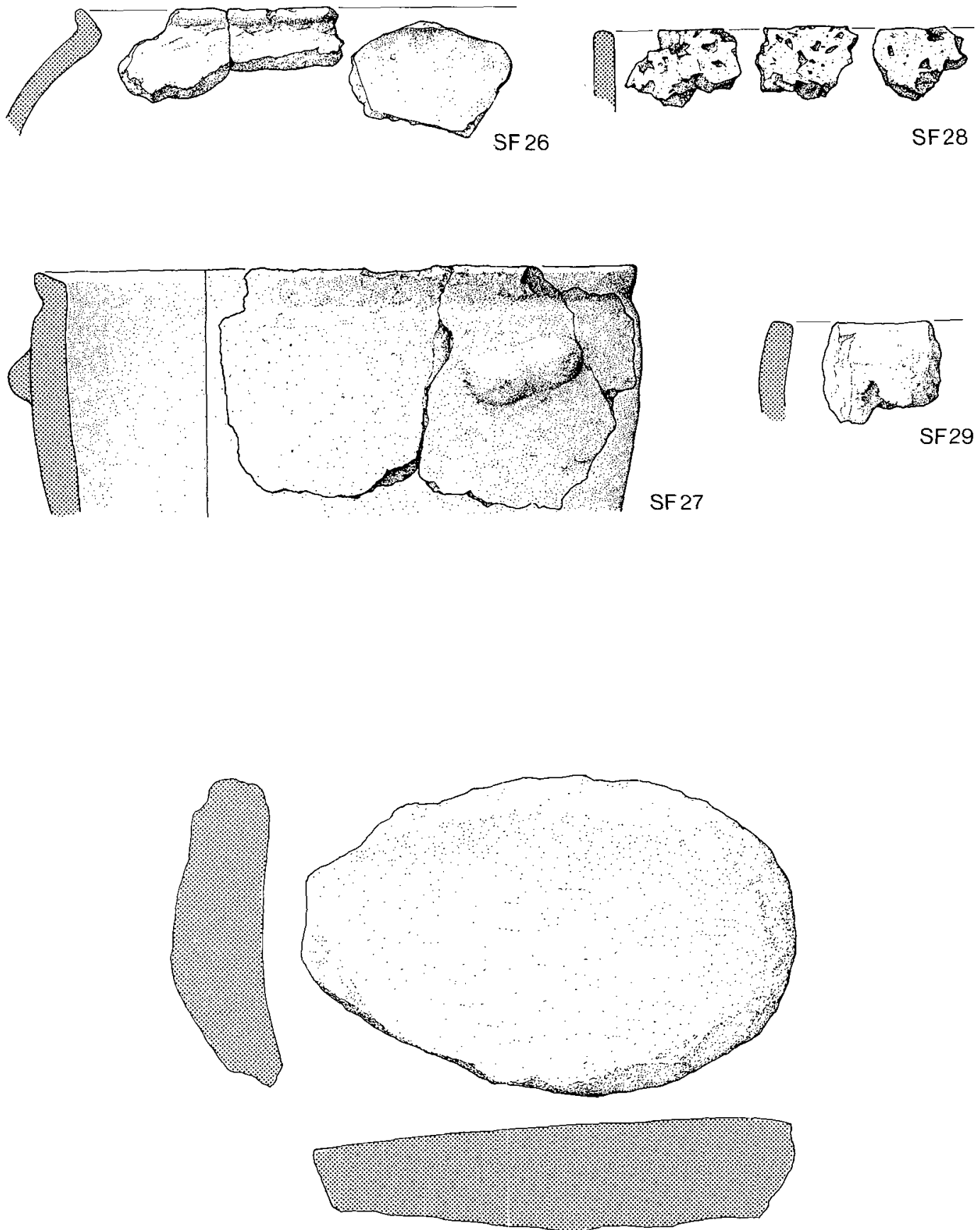

SF 32

ILLus 28 Pottery (scale 1:2); quern (scale 1:8) 

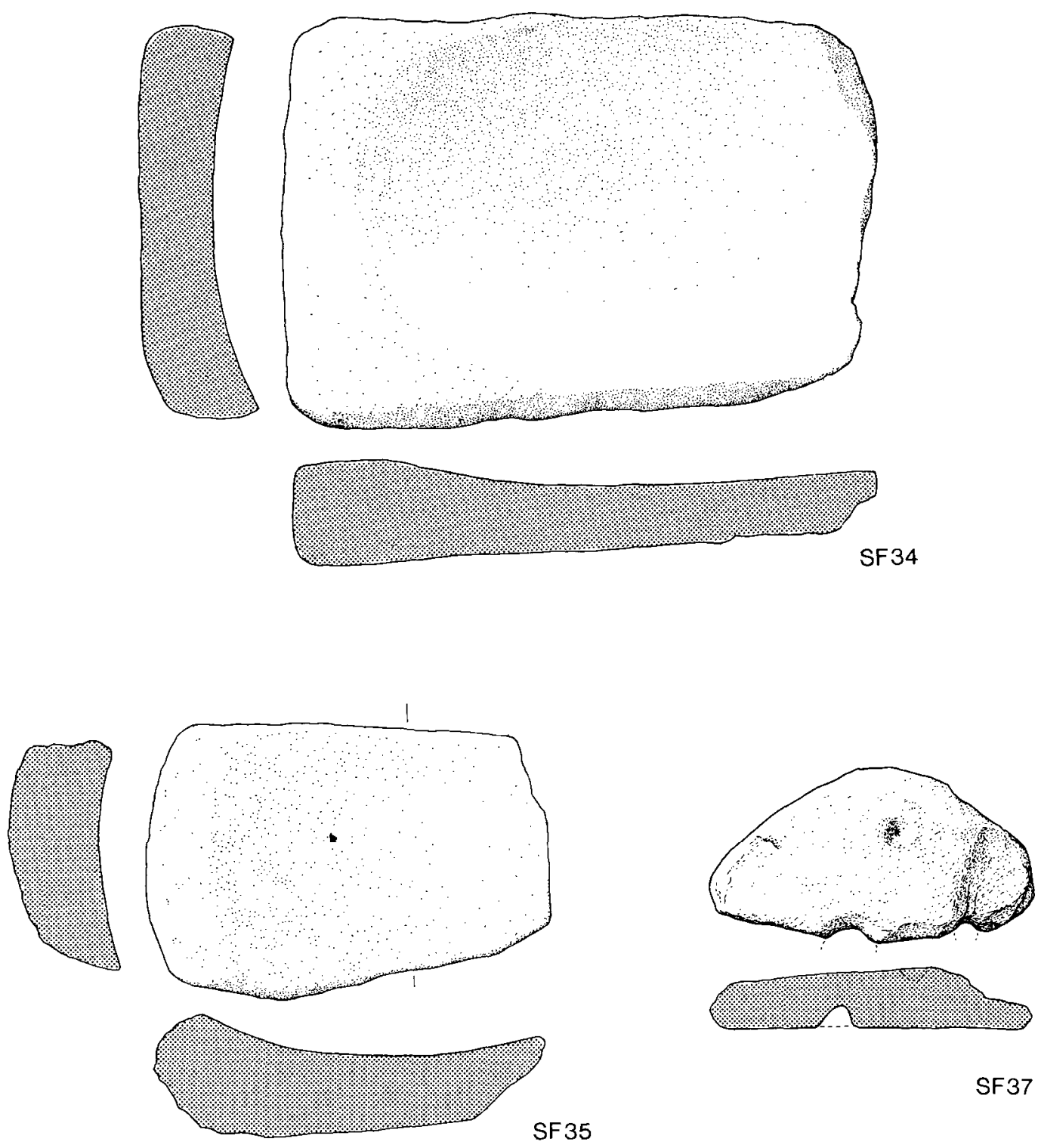

SF37

ILLUS 29 Querns (scale 1:8)

SF37 Half of a broken rotary quern, originally c $360 \mathrm{~mm}$ in diameter. The broken edge measures $340 \mathrm{~mm}$. Two holes lie on the line of the break; one, approximately central, is a little over $40 \mathrm{~mm}$ in diameter, the other lies $70 \mathrm{~mm}$ from the edge of the quern and is a little over $25 \mathrm{~mm}$ in diameter. On the upper surface is a small depression c $10 \mathrm{~mm}$ deep and $25 \mathrm{~mm}$ in diameter. The lower surface of the quern is smoothed. It is suggested that the two holes on the line of break are the central and handle holes and that the depression on the upper surface marks an abandoned attempt at piercing the quern a third time. The quern was found in a later context and may be relatively recent. 
MISCELLANEOUS

SF38 Trapezoidal stone with one smoothed side, measuring $182 \mathrm{~mm}$ by $108 \mathrm{~mm}$ by $71 \mathrm{~mm}$.

SF39 A conical baked clay object measuring $44 \mathrm{~mm}$ long and between $36 \mathrm{~mm}$ and $50 \mathrm{~mm}$ across.

SF40 A roughly triangular flint flake, with 6 facets, one of which displays cortex, measuring $15.5 \mathrm{~mm}$ long, $15 \mathrm{~mm}$ broad and $5 \mathrm{~mm}$ deep. There is no obvious retouch.

SF41 A quartz fragment, possibly worked, measuring $32 \mathrm{~mm}$ long by $17.5 \mathrm{~mm}$ broad, by $7 \mathrm{~mm}$ deep.

SF42 A rectangular stone with two smoothed sides, measuring $139 \mathrm{~mm}$ long by $49 \cdot 5 \mathrm{~mm}$ broad and $31 \mathrm{~mm}$ deep. Possibly a whetstone.

SF43 Roughly rectangular, flat sided soft sandstone block with one smoothed platform, measuring 112 $\mathrm{mm}$ long, by $45 \mathrm{~mm}$ broad and $68 \mathrm{~mm}$ deep.

\section{4: ROCK SPECIMENS}

\section{G H Collins}

Nineteen specimens excavated at Suisgill were submitted. All of them could be matched with rocks outcropping within 20 miles of the site. The majority are mica-schists and granulites similar to rocks of Moinian age upon which the excavation is sited.

Three of the specimens are composed of sandstone which may be matched with specimens of (Middle Old Red Sandstone) Devonian Age from Caithness. Another three specimens are of black shale which, whilst it is possible that they originated further afield, can be found associated with the brown coals of Jurassic age in the Golspie-Brora district.

Most of the specimens are water-worn, suggesting that they are worked erratic blocks.

\section{5: CARBONIZED PLANT REMAINS}

\section{$M$ van der Veen}

\section{INTRODUCTION}

Thirty-three samples taken from various contexts were floated by the excavator, using a $5 \mathrm{~mm}, 2$ $\mathrm{mm}, 1 \mathrm{~mm}$ and $0.5 \mathrm{~mm}$ sieve stack. The floats were presented to the writer for analysis. Twenty-three samples contained carbonized plant remains other than charcoal and two samples contained waterlogged material. Tables 2 and 4 list the identifications.

\section{RESULTS}

Barley The barley remains consisted of both grains (many badly preserved) and some rachis internodes. The ratio of central to lateral grains (using only the well preserved ones) was 1:1. In six-row barley this ratio is 1:2 and in two-row barley 2:0. The equal numbers of central and lateral grains in these samples could indicate that both species were present. The rachis internodes, however, all clearly belong to the six-row variety, which would suggest that the lateral grains are under-represented.

Only five grains showed the characteristic features of hulled barley: clear parallel ridges on the dorsal surface and a slightly angular cross-section; another 10 grains showed faint ridges. The majority of the grains, however, were rounded in cross-section and about one-third of them showed the fine transverse wrinkling on the surface as described by Van Zeist $(1968,50)$.

The majority of the barley in the samples is therefore six-row naked barley, Hordeum vulgare, var nudum, with only a small representation of the hulled, six-row barley, Hordeum vulgare.

Wheat Only seven grains of wheat and no chaff fragments were found. Wheat grains cannot be reliably identified to species-level on the basis of grain shape alone (Jones 1978, 103). In the absence of chaff fragments the grains have been tentatively identified as one Triticum cf aestivum (bread wheat) and one hexaploid wheat. The other grains could only be classified as Triticum $\mathrm{sp}$.

Oats A total of 32 oat grains was found. In the absence of the flower-bases no reliable identifications can be made. Characteristics like size and shape cannot be used satisfactorily, as the size ranges of wild and cultivated oats are not mutually exclusive. Measurements of the Suisgill grains are given in Table 3. They fall within the range of cultivated oats (either Avena sativa or Avena strigosa), but also fit at the top end of Avena fatua, wild oat (Jessen \& Helbaek 1944, 49-50; Van Zeist 1968, 86, 107, 146). One grain showed a broadly V-shaped, deep ventral furrow, and might belong to Avena fatua (Jessen \& Helbaek 


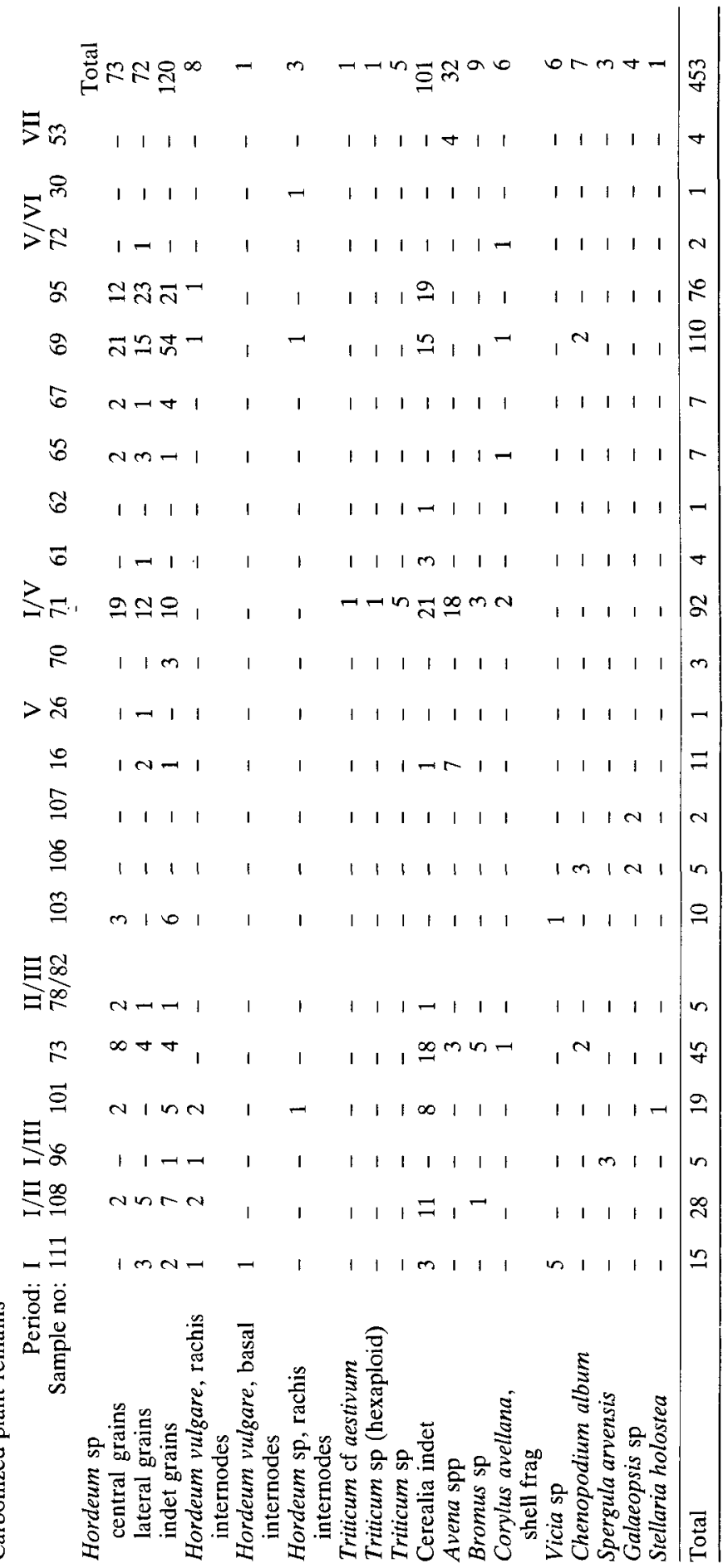


TABLE 3

Dimensions in mm of oat grains

\begin{tabular}{|c|c|c|c|}
\hline & $\mathrm{L}$ & B & $\mathrm{T}$ \\
\hline \multirow[t]{7}{*}{ Sample 16} & 6 & $1 \cdot 8$ & 1.5 \\
\hline & $5 \cdot 4$ & $2 \cdot 1$ & $1 \cdot 8$ \\
\hline & 6 & $2 \cdot 1$ & 1.95 \\
\hline & $5 \cdot 55$ & $2 \cdot 1$ & $1 \cdot 8$ \\
\hline & 6 & $2 \cdot 25$ & $2 \cdot 1$ \\
\hline & $5 \cdot 4$ & $1 \cdot 8$ & $1 \cdot 5$ \\
\hline & $4 \cdot 8$ & $1 \cdot 8$ & - \\
\hline \multirow[t]{4}{*}{ Sample 53} & $6 \cdot 45$ & $1 \cdot 95$ & 1.95 \\
\hline & $4 \cdot 8$ & $1 \cdot 8$ & 1.65 \\
\hline & $4 \cdot 2$ & $1 \cdot 65$ & $1 \cdot 5$ \\
\hline & $6 \cdot 15$ & 1.95 & - \\
\hline \multirow[t]{14}{*}{ Sample 71} & $5 \cdot 55$ & $2 \cdot 1$ & $1 \cdot 8$ \\
\hline & $5 \cdot 85$ & $2 \cdot 1$ & $2 \cdot 25$ \\
\hline & $6 \cdot 15$ & $2 \cdot 4$ & 1.65 \\
\hline & 6 & $2 \cdot 1$ & $2 \cdot 25$ \\
\hline & $5 \cdot 55$ & 1.95 & $1 \cdot 8$ \\
\hline & $6 \cdot 15$ & $2 \cdot 1$ & 1.95 \\
\hline & $5 \cdot 55$ & 1.95 & 1.65 \\
\hline & $4 \cdot 8$ & $1 \cdot 8$ & $1 \cdot 35$ \\
\hline & $6 \cdot 15$ & - & - \\
\hline & $6 \cdot 3$ & $2 \cdot 25$ & 1.95 \\
\hline & $6 \cdot 3$ & 1.95 & $1 \cdot 8$ \\
\hline & $5 \cdot 7$ & $1 \cdot 8$ & $1 \cdot 65$ \\
\hline & - & $1 \cdot 65$ & $1 \cdot 35$ \\
\hline & $4 \cdot 5$ & $1 \cdot 65$ & $1 \cdot 5$ \\
\hline Sample 73 & $4 \cdot 65$ & $1 \cdot 8$ & - \\
\hline
\end{tabular}

1944, 52-3). Grains of Avena sativa often have their greatest thickness and greatest breadth below the middle (Jessen \& Helbaek 1944, 49); approximately one-third of the Suisgill grains possess this feature.

It is, therefore, not possible to identify the Suisgill oats, although there are hints that the cultivated variety is at least present.

\section{DISCUSSION}

Naked barley is the dominant crop plant in the samples, representing more than half of the total number of grains recovered. In the English later Bronze Age an increase in the occurrence of hulled barley at the expense of naked barley has been recorded. A similar development is noted in Denmark and the Netherlands. In the Netherlands naked barley is absent after the mid first millennium BC, while in Denmark this shift occurs during the first half of the first millennium AD (Helbaek 1952; Van Zeist 1968). No satisfactory explanation for this shift has yet been put forward. It is interesting that the Suisgill samples, dated to $c 850 \mathrm{bc}$, still contain only a trace of hulled barley. The significance of wheat as a crop plant at Suisgill is difficult to assess in the absence of comparative material.

Both wild and cultivated oats are first recorded in England in the first half of the first millennium BC. Most are only dated by associated pottery assemblages, but one series of mid first-millennium bc radiocarbon dates is available for cultivated oats from Dinorben fort, North Wales (Jones 1981, 104). In southern Britain the introduction of oats, together with spelt and bread wheat, has been associated with population increase and the resultant cultivation of marginal land (Jones 1981). It is not yet possible to establish whether this development also took place in the highland zone. Oats have a high tolerance to acid and infertile soils, which makes it a crop plant especially suited to upland regions. Wild oats, especially Avena fatua, is often found as a weed in arable fields. As the oat grains in the samples are not associated with other arable weeds and/or chaff fragments, but mainly with other crop plants, this could be taken as an indication that oat was grown as a crop in its own right.

Bromus (chess), Vicia (vetch), Chenopodium album (fat hen), Spergula arvensis (corn spurrey) and Galeopsis (hemp-nettle) are all common weed species that occur in arable fields or on waste places. 
Stellaria holostea (satin flower) grows in woods and hedgerows. The presence of Corylus shell fragments points to the collection of hazelnuts.

Two samples of waterlogged plant remains were collected, no 29 and 32 (table 4). They consisted of weed species only. All of them grow on waste places and in arable fields.

\begin{tabular}{llc} 
TABLE 4 & & \\
Waterlogged plant remains & \multicolumn{2}{c}{ Sample No } \\
& 29 & 32 \\
& 2 & - \\
Polygonum convolvulus & 81 & 30 \\
Polygonum aviculare & 15 & - \\
Chenopodium album & 4 & - \\
Stellaria media & 2 & - \\
Ranunculus sp & 1 & 2 \\
Galeopsis sp & 1 & - \\
Spergula arvensis & 1 & - \\
Indeterminate &
\end{tabular}

The presence or absence of certain categories of harvest refuse (straw and chaff fragments and weed seeds) is often used to detect the origin of the plant assemblage, and to answer questions concerning the role of crop husbandry on the site, as activities like production or consumption generate different plant assemblages. The Suisgill plant remains appear to represent the residues of a fully processed crop as virtually no harvest refuse was found. This would suggest that either no harvest refuse was ever present on the site, implying that the cereals were not locally produced or, alternatively, that the harvest refuse was not deposited in the small part of the site excavated, implying that the plant remains are only representative of the area excavated, but not of the site as a whole. Without a larger sample from the settlement it is not possible to make any reliable inferences about the role of crop production at Suisgill (Hillman 1981; Van der Veen 1984). However, the presence of ardmarks in certain phases of the site would suggest that, at least during those phases, some crops were locally produced.

\section{6: A SUMMARY OF THE RADIOCARBON-DATED VEGETATIONAL HISTORY OF THE SUISGILL AREA}

\section{V Andrews, A M Blackham and D Gilbertson*}

The full report is on fiche 1:C3-D4. This section summarizes pollen analytical studies from the blanket bog on Cnoc Bad na h-Eirig, at $183 \mathrm{~m} \mathrm{OD,} 2 \mathrm{~km}$ from the Suisgill site. Two pollen diagrams are described with the aid of three radiocarbon dates and a series of local pollen assemblage zones recognized in the profiles. Peat formation began approximately 6700 years ago. From this time until shortly before $4450 \mathrm{bp}$, the vegetation of the area comprised open woodland dominated by pine and birch, with smaller frequencies of oak and elm. This was interspersed with open heather moorland and wet acid bog. Alder expanded rapidly in this period, reaching a maximum abundance at a time estimated to be approximately $5600 \mathrm{bp}$.

Shortly before $4450 \mathrm{bp}$, the forest cover declined notably, with the complete elimination of elm and reduced frequencies of birch, pine, and alder. This change was associated with the spread of taxa characteristic of open and disturbed habitats and acid bogs. The cause of these changes cannot be identified with certainty: they may be due to a combination of factors, including Neolithic clearances and hydrologically- or climatically-induced variations in the wetness of blanket bog at the coring site.

Subsequently, a significant regeneration of the forest cover occurred, with pine and birch becoming almost totally dominant; heathland continued to be important. Shortly before $1700 \mathrm{bp}$, a notable reduction in the pine-birch forest took place, with heath-covered moorland becoming more widespread and this typified the vegetation from this point until the present day. However, minor 
changes are recorded in the uppermost parts of the pollen diagram, where small-scale regeneration of woodland species might be attributable to the Highland Clearances.

The vegetation of the area at the time of the Suisgill settlement (at approximately $630 \mathrm{bc}$ ) was dominated by open pine-birch woodland, interspersed with open heathland. This occupation might be associated with the clearance episode recorded in the pollen diagram.

The vegetational changes recorded are very broadly similar to those noted elsewhere in northeastern Scotland.

\section{7: RADIOCARBON DATES}

M J Stenhouse and G Cook*

Laboratory Raw Date
No

\begin{tabular}{|c|c|c|c|}
\hline GU-1326 & $630 \pm 60 b c$ & Alnus & $\begin{array}{l}\text { Period V. Twigs and small branches preserved in } \\
\text { gravel wash. }\end{array}$ \\
\hline GU-1490 & $885 \pm 90 b c$ & Betula/Alnus & Period IV. Burnt post of Structure 2. \\
\hline GU-1491 & $255 \pm 65 \mathrm{bc}$ & $\begin{array}{l}\text { Betula/Alnus/ } \\
\text { Corylus }\end{array}$ & Period VI. Charcoal in occupation layer. \\
\hline GU-1492 & $825 \pm 105 b c$ & Betula & Period II. Charcoal from posthole of House 1a. \\
\hline GU-1493 & $990 \pm 60 b c$ & Betula & $\begin{array}{l}\text { Period IV. Burnt stakes on top of primary settle- } \\
\text { ment boundary bank. Probably part of House } 2 \text {. }\end{array}$ \\
\hline
\end{tabular}

\section{8: INTERPRETATION AND DISCUSSION}

The deep stratigraphy at Suisgill preserved a record of part of the use of a small area of the terrace of the Helmsdale river. However, the area available for excavation was very restricted, and had been subjected to episodes of very severe disturbance by both human and natural agencies. Further, very different rates and standards of excavation were possible on different part of the site.

This report, therefore, deals with a small sample of a portion of a complex landscape over a period of at least 2500 years; a sample, moreover, which greatly varies in quality from place to place and period to period on the site. It is possible to describe the chronological sequence of this narrow strip but the history and nature of the whole settlement and of the landscape in which it lay remain obscure, though light is cast on the development of the landscape by the general pollen core from the vicinity of the site, and on the interpretation of the processes which led to the burial of the site.

The interpretation of the excavation evidence has, because of the nature of the site, influenced the arrangement of the 'Description' section, and has, to a great extent been presented in that section. Therefore, this part of the report discusses the interpretation of individual features, groups of features, results of specialist work, and the site as a whole. Brief mention is made of the processes which led to the burial of the site. Because of the extreme paucity of comparable sites, discerned by field survey or excavation, little is presented on this subject: distant comparanda have not been dredged up in the absence of local material. Fairhurst and Taylor's (1971) words about the state of research at the time of their excavation still ring very true: 'Until our investigations started, only two sites within the country had been excavated and the reports were so vague as to be almost useless'.

*Department of Chemistry, University of Glasgow 
The same is the case for Suisgill earlier in the millennium. However, the publication of recent work at Kilearnan and at Crosskirk should further develop later Bronze Age and Iron Age studies.

As in earlier parts the Interpretation and Discussion is split into sections:
A Agricultural traces
B Structures
C Landscape History
D Artefacts

\section{A: Agricultural Traces}

The evidence for agricultural activity is limited to the presence of groups of ard-markings, a few possible spade-marks, quantities of carbonized cereal grains and some saddle querns.

\section{1: Cultivation traces}

It has been suggested (Reynolds 1981) that some at least of the many sets of ard-markings found on excavations are not the result of regular tillage but were caused by periodic episodes of breaking grassland, tillage being achieved by using lighter ards, spades or hoes. The intensity of marks in certain parts of the site at Suisgill might suggest continuous ard cultivation. However, the evidence is not conclusive; no clue can be gained to the period over which the marks accumulated. The largescale build up of topsoil at the south edge of the trench resulted from gradual downhill creep, a process exacerbated by lack of vegetation cover. It has been shown that ard-marks appeared in a sand lens high in the topsoil build-up, indicating the continuation of the arding process (whatever it was).

\section{2: Carbonized Cereals}

Van der Veen has discussed the significance of the cereal remains in Section 5. The majority of grains were recovered from Period I-IV contexts; from Period VI onwards little appeared. Therefore a clear picture has emerged only for the first part of the occupation of the site, prior to the first gravel inundation in the mid first millennium bc.

Throughout Periods I-V naked and hulled six-rowed barley occurred, although the latter was found only in small quantities; barley was, overall, the commonest crop recovered. Domesticated oats were found in Period I-III contexts, Period VII and, mostly, in Period VI. The little wheat recovered was found in a Period V context.

Little comparative material is available from northern Scotland. The barley predominanace is not unusual in Scottish LBA/IA contexts. The appearance of domesticated oats in the mid to late first millennium bc is consistent with the limited evidence available. No crop processing debris was recovered; Van der Veen has suggested that the remains represent traces of fully processed crops (Hillman 1981).

The limited information available on the dates of introduction and the dates for the lapse of use for the various cereal crops has recently been summarized (with firmly expressed reservations) by Hillman (1981). The map illustrating the 'Distribution of Iron Age Sites with specific crop records' reproduced in Jones (1981), though omitting a few published Scottish finds of cereal remains, presented a generally accurate picture of our knowledge of crop husbandry at that time. Recently further examples have been published; in the near future important assemblages will be presented and it is to be hoped that a useful assessment of crop history in the north will be available later in the decade. 


\section{B: STRUCTURES}

\section{1: Houses}

The fragmentary remains of the Period IV building preclude any discussion of its form. The area of burnt material interpreted as indicating the extent of the house is $10.5 \mathrm{~m}$ to $11 \mathrm{~m}$ in diameter, but this cannot be taken as a firm indication of the original extent of the structure.

However, rather more survives of the earlier buildings, of Period II. The evidence seems to indicate the presence of two buildings, the second of which may have been an extensive refurbishment of the first. Additionally, further posts may have been replaced more often, leading to an even greater complication. An irregular, shallow ditch, containing much tumbled stone, covering a complex series of recut postholes, may represent either the main structural element of the house (holding the roof up), the outer wall having left no archaeological trace (as at Myrehead: Barclay 1984), or be the foundations of such an outer wall, the roof being held up by the posts within the enclosed area. Some of the features may be truncated elements of the Period IV building. There was insufficient time during the salvage season to answer these questions.

Unless a surrounding stone or soil ring had been removed in the course of or to allow prehistoric tillage, the buildings cannot be interpreted as 'hut circles', the ubiquitous Iron Age house type in northern Scotland. Beyond the similarity in the shape of the hearth in 'house I' they cannot apparently be compared with the later hut circles excavated at Kilphedir (Fairhurst \& Taylor 1971). Artefact similarities are dealt with below.

\section{2: Souterrains}

The three souterrains found in close proximity to the site fall into two distinct classes. Suisgill I, on the other side of the burn, is a long narrow curving passage typical of most northern souterrains. Suisgill III, the cruciform souterrain, has only one parallel, at Kirkton near Golspie, which differs in some ways from Suisgill III; notably it has two entrances and elaborate door checks. Suisgill II, of which only a fragment survives, could be the remnants of a souterrain similar to I, but it could also be the remains of a curving main chamber of a souterrain similar to number III.

No detailed survey of the northern souterrains has been published. Wainwright, in his general paper on the subject (1953), briefly outlined the characteristics of the northern souterrains. Grealey, in an unpublished MA dissertation (1972) recatalogued the sites but provided only a general description of the characteristics and associations.

Suisgill III could not be related to the site stratigraphically, but only by radiocarbon dating. It appears to fall in the mid first millennium bc, rather earlier than souterrain dates in the south would lead us to expect. As no other souterrains have been dated on the northern mainland no comparanda are offered. It should be noted that the Rosal souterrain (Corcoran 1968) bears no resemblance to the Suisgill examples. The souterrain at Fouhlin was excavated in 1964 and 1965: no final publication has yet appeared (Discovery Excav Scot 1964, 51; 1965, 39).

Suisgill III may have been associated with the line of stones discovered immediately to the north of the entrance passage. It is possible that the souterrain was entered from a hut circle, of which the stone line was a fragment: this arrangement is very common among the northern souterrains, and can be paralleled in the South, eg at Newmill (Watkins 1980).

\section{3: Land divisions and the enclosure}

A great variety of demarcation features survived on the site, ranging from the single line of stones, possibly marking a cultivation plot at the east end of the site in Period V, to the substantial stone-faced boundary bank and its stone refurbishment of Periods II to V. 
The stone-faced earth bank seems not to have been large enough to act as a defensive structure, nor did it bear any substantial breastwork. The bank and the possible fence along its peak may have served only to keep wild or domestic animals out of the core of the settlement. It can be traced as a low bank on the surface to the north-west; it appears to cut off an area $50 \mathrm{~m} \mathrm{NW-SE}$ and $70 \mathrm{~m} \mathrm{NE}-\mathrm{SW}$ backing on to the Burn at the north-west. No similar enclosures have been excavated and few immediately comparable ones have been found by field survey (and those remain undated). Mercer's recent surveys $(1980 ; 1981)$ have produced a number of enclosures and settlement complexes which might compare with Suisgill: eg the Borg Broch complex (Mercer 1980, FON 41, fig 12), Halladale (Mercer 1980, Hal 26, fig 33), Sandside complex (Mercer 1981, fig 18) but without excavation no conclusions can be drawn.

At one stage, in Period VI, the main flood channel across the site was defined by a wall on both of its banks, and before this an enigmatic post- and stake-line had been inserted into the washed-down gravel. The function of the walls is obscure; it may be suggested that they were built to restrict the flow of flood water to the channel.

Also in Period VI fences and a light wall had been inserted to the south of the wall along the watercourse; their function in the organization of the settlement at that time remains obscure.

\section{C: LANDSCAPE HISTORY}

A general picture of the landscape during the whole of the occupation of the site has been provided by the pollen analysis of a peat column taken from $c 2 \mathrm{~km}$ to the north-east of the site. This analysis is described in detail on the fiche 1:C3 and is summarized above (Section 6). The portion of the column relevant to the excavated settlement shows a landscape dominated by open pine-birch woodland, interspersed with open heathland; the Suisgill settlement may be associated with an episode of clearance recorded in the pollen profile. The authors have noted that the changes recorded are broadly similar to those found elsewhere in the north. A radiocarbon-dated column is being examined in conjunction with the recent excavation at Kilearnan (Haggarty, pers comm). Two undated short profiles were analysed at the excavation at Kilphedir (Fairhurst \& Taylor 1971) and are relevant in general only to the Kilphedir settlement itself. Although no conclusions on climate change during the occupation of the settlement have been drawn from the pollen results, it is possible that an indication of increased rainfall is given by the scale of water erosion and the deposition of gravel on the site.

The most recent surveys of the processes and archaeological implications of valley sedimentation and erosion have been by Bell $(1981 ; 1982)$. Lamb $(1981)$ has briefly summarized the evidence for climatic change in the period under review. The deposition of material on the Suisgill site was by alluvial processes, that is material borne by water from the hillslope to the east. Bell has pointed to the importance of devegetation as an encouragement to erosion. It is possible that the erosion to the east of the Suisgill site began with such devegetation, where there is a hollow, running down from the plateau, which lies above the terrace. The modern estate access coincidentally runs close to it; this modern path, though used only infrequently by light cross-country vehicles, is heavily eroded and acts as a watercourse in wet weather. It is tentatively suggested that the prehistoric erosion might have begun in the same way; perhaps an access to the plateau extensively used by stock developed into a watercourse during heavy rainfall. Bell (1982) has pointed out that the greater part of a deposit of erosion material may be removed and redeposited during major storms, rather by a gradual process. The deposition pattern in the two main episodes of erosion on the site suggests that the gravel was laid down in a series of minor events, the two major episodes being separated by the temporary stabilization which allowed the establishment of the Period VI settlement partly on the gravel. The gravel layers could represent the action of the storms over several decades. There were fragmentary 
remains of further occupation on the temporarily stable gravels. The build-up of topsoil at the south corner of the excavated area would suggest severe erosion from the hill to the east: given the evidence for tillage it seems likely that the build-up is a lynchet at the bottom of a hill field. The upper part of the field would have been stripped of topsoil eventually by the water washing which preceded and accompanied the gravel deposition.

The archaeological implications of the Suisgill site for Highland Scotland are significant. A hitherto unrecognized type of house and enclosure, of a period apparently very badly represented in the upstanding remains (but see Barber's forthcoming report on Arran for Bronze-Age hut circles) was found on a river terrace, consistently the most heavily exploited type of land in the north, and therefore an area in which poor survival of monuments would be expected. A stratigraphy of almost $2 \mathrm{~m}$ was preserved, representing a cross-section of settlement evidence over a period of over 2500 years. Although water damage was severe in a large part of the excavated area, the portion of the site lying to the south-west of the trenches should preserve relatively undamaged evidence under the protecting blanket of gravel. It is certain that other sites buried by colluvial and alluvial processes survive in Highland and other valleys. It is a truism that archaeological information of an immensely better quality is available from sites where the more fleeting remnants of settlement and ritual activity survive (such as floors, stakeholes, hearths), than from sites which have been ploughed or otherwise abraded. The discovery of further well-preserved sites buried under hillwash is a most exciting prospect. However, the problems of location and preservation are great.

\section{D: ARTEFACTS}

The pottery recovered from Suisgill can be compared with material from Kilphedir (Fairhurst \& Taylor 1971) and from the recent excavations at Kilearnan (Haggarty, pers comm). Notably the everted-rim pottery appears in similar forms on all three sites, although the Kilearnan fabric is superficially different: the Kilphedir pottery could not be located for comparison and no radiocarbon dates were available for Kilearnan at the time of writing. The Kilphedir pottery is dated to the later part of the first millennium bc, but it is clear that similar styles, including possibly some flat-rimmed types, had remained in use from the early/mid to the later first millennium bc.

$S F 27$, the lugged vessel, is an anomaly. It is the only member of its fabric group and, unless a slight similarity in the treatment of the zone under the rim and that on some of the everted-rim pots is accepted, it has no stylistic parallel in the assemblage. It is suggested that the vessel has one of two possible backgrounds: firstly that it is a Neolithic/Bronze Age vessel which has found its way on to the site or that it is a later Bronze Age domestic vessel reflecting earlier traits. Our knowledge of both possible backgrounds in mainland northern Scotland is so deficient that no conclusion can be drawn for the moment.

Clarke (1980) in his seminal paper on the models used in the interpretation of the Scottish Iron Age dismissed the quasi-historical explanations of widespread phenomena (eg MacKie 1970). He stated that 'it is not too exaggerated to say that our present views on Iron Age Scotland are based on only a tiny proportion of the available evidence .... While this author agrees with Clarke's warning that in the early stage excavation and survey should not be mere data collection (without thought for the models to explain the data), an irnmense amount of work remains to be done on the northern mainland before we possess sufficient basic data on chronology, artefact types, settlement types and economic systems to allow a start to the real process of understanding the prehistoric peoples of this area. The excavations at Kilphedir, Suisgill, Kilearnan and Crosskirk, combined with the surveys of Mercer and others, are the first modern steps on the long road to an understanding of the later prehistory of the northern mainland of Scotland. 


\section{ACKNOWLEDGEMENTS}

The excavation could not have taken place without the very active assistance of Highland Regional Council, especially the Divisional Engineer, Mr Morris Taylor, the Council's consultant engineers, Bullen \& Partners per Mr Gordon Pomphrey, and, most notably, Suisgill Estate per the factor and his wife, Mr and Mrs M McGillivray, and the owner, Mr Reeve, to all of whom the author wishes to extend his thanks. The site staff, James Rideout (the assistant supervisor), Jill Harden, Derek Hall and Margaret Rideout, together with the volunteers also deserve great thanks, especially those who worked on the last season. My thanks also to Orlando Elmhurst, of Bradford University, for carrying out the resistivity survey.

I must also thank the specialist contributors, whose work had added greatly to the value of the report; Marijke van der Veen - seed identification, Martha Andrews, David Gilbertson and Anne Blackham - pollen analysis; Jenny Lee - pottery description and fabric analysis; James Rideout - site illustrations; Angie Townshend - find illustrations, Rosemary Cowie - find cleaning and consolidation (under the general supervision of Richard Welander of IAM laboratory); Derek Hall - postexcavation processing; John Barber and Rod McCullagh - wood and charcoal; Michael Stenhouse radiocarbon dating; Geoffrey Collins - stone identification. My thanks are due to those who have read and commented on the report during and after its preparation, David Breeze, then in charge of rescue archaeology within the SDD, James Rideout and John Barber, these also for their general advice and support.

\section{REFERENCES}

Barclay, G J 1983 'The excavation of a settlement of the Later Bronze Age and Iron Age at Myrehead, Falkirk District', Glasgow Archaeol J, 10 (1983), 41-71.

Bell, M 1981 'Valley sediments and environmental change', in Jones \& Dimbleby 1981, 75-91.

Bell, M 1982 'The effects of land-use and climate on valley sedimentation', in Harding, A F (ed), Climate Change in Later Prehistory, Edinburgh, 127-42.

Birks, H J B 1977 'The Flandrian forest history of Scotland: a preliminary synthesis', in Shotton, F W (ed), British Quaternary Studies, Oxford, 119-35.

Bunce, R G H \& Jeffers, J N R 1977 Native Pinewoods of Scotland. Cambridge.

Clark, R M 1975 'A calibration curve for radiocarbon dates', Antiquity, 49 (1975), 251-66.

Clarke, D V 1980 'Models and Research Priorities in Scottish Iron Age Studies', Scot Archaeol Forum, $10(1980), 76-9$.

Corcoran, J X W P 1968 'The souterrain at Rosal, Strath Naver, Sutherland', Proc Soc Antiq Scot, 100 (1967-8), 114-18.

Curle, A O 1911 'On the excavation of two hut circles in the Strath of Kildonan, Sutherlandshire, one of which has an earth house attached', Proc Soc Antiq Scot, 45 (1910-11), 18-26.

Fairhurst, H 1971 'Kilphedir and hut circle sites in Northern Scotland', Scot Archaeol Forum, 3 (1971), $1-10$.

Fairhurst, H 1984 Excavations at Crosskirk Broch, Caithness. Edinburgh. (=Soc Antiq Scot Monogr Ser, 3.)

Fairhurst, H \& Taylor, D B 1971 'A hut circle settlement at Kilphedir, Sutherland', Proc Soc Antiq Scot, 103 (1970-71), 65-99.

Godwin, H 1975 The History of the British Flora. Cambridge.

Grealey, S 1972 The Souterrains of Great Britain and Ireland. (MA thesis presented to Univ Liverpool.)

Helbaek, H 1952 'Early crops in Southern England', Proc Prehist Soc, 18 (1952), 194-233.

Hillman, G 1981 'Reconstructing crop husbandry practices from charred remains of crops', in Mercer, R J (ed), Farming Practices in British Prehistory, Edinburgh, 123-62.

Jessen, K \& Helbaek, H 1944 'Cereals in prehistoric and early historic times', Det Kongelige Danske Videnskabernes Selskab, Biologistic Skrifter, Bind III, 3 (1944), 1-69. 
Jones, M 1978 'The plant remains', in Parrington, M (ed), The Excavation of an Iron Age Settlement, Bronze Age Ring Ditches and Roman Features at Ashville Trading Estate, Abingdon (Oxon) 1974-76, London, 93-101. (=Counc Brit Archaeol Res Rep, 28.)

Jones, M 1981 'The development of crop husbandry', in Jones \& Dimbleby 1981, 95-127.

Jones, M \& Dimbleby, G (eds) 1981 The Environment of Man: the Iron Age to the Anglo-Saxon Period. Oxford. (=Brit Archeol Rep, 87.)

MacKie, E W 1970 'The Scottish Iron Age', Scot Hist Rev, 49 (1970), 1-32.

Mercer, R J 1980 Archaeological Field Survey in Northern Scotland 1976-1979. Edinburgh. (=Univ Edinburgh, Dept of Archaeol, Occas Pap, 4.)

Mercer, R J 1981 Archaeological Field Survey in Northern Scotland, Volume II 1980-1981. Edinburgh. (=Univ Edinburgh, Dept of Archaeol Occas Pap, 7.)

O'Sullivan, P E 1974 'Two Flandrian pollen diagrams from the east-central Highlands of Scotland', Pollen et Spores, 16 (1974), 33-57.

O'Sullivan, P E 1976 'Pollen analysis and radiocarbon dating of a core from Loch Pityoulish, eastcentral Highlands of Scotland', J Biogeogr, 3 (1976), 293-302.

O'Sullivan, P E 1977 'Vegetation history and native pinewoods', in Bunce, R G H \& Jeffers, J N R (eds), Native Pinewoods of Scotland, Cambridge, 60-9.

Pennington, W 1972 'Lake sediments in Northern Scotland', Phil Trans Roy Soc London, B, 246 (1972), 191-294.

Piggott, S 1972 'A note on the climatic deterioration in the first millennium BC in Britain', Scot Archaeol Forum, 4 (1972), 109-13.

Reynolds, P J 1981 'Deadstock and Livestock', in Mercer, R J (ed), Farming Practice in British Prehistory, Edinburgh, 97-122.

RCAMS 1911 Royal Commission on the Ancient Monuments of Scotland, Inventory of Monuments and Constructions in the County of Sutherland. Edinburgh.

Shepard, A O 1956 Ceramics for the Archaeologist. Washington DC.

Veen, Marijke van der 1984 'Sampling for seeds', in Zeist, W van \& Casparie, W A (eds), Plants and Ancient Man, Studies in Palaeoethnobotany, Rotterdam, 193-9. (=Proc VI Symposium. Int Workshop Palaeoethnobotany.)

Wainwright, F T 1953 'Souterrains in Scotland', Antiquity, 27 (1953), 219-32.

Wainwright, F T 1963 The Souterrains of Southern Pictland. London.

Watkins, T F 1980 'Excavation of a settlement and souterrain at Newmill, near Bankfoot, Perthshire', Proc Soc Antiq Scot, 110 (1978-80), 165-208.

Zeist, W van 1968 'Prehistoric and early historic food plants in the Netherlands', Palaeohistoria, 12 (1968), 41-173.

This paper is published with the aid of a grant from Historic Buildings and Monuments (SDD) 